Canadian

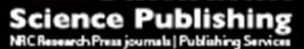

Canadian Journal of Civil Engineering Revue canadienne de génie civil

\title{
Distortional Lateral Torsional Buckling for Simply Supported Beams with Web Cleats
}

\begin{tabular}{|r|l|}
\hline Journal: & Canadian Journal of Civil Engineering \\
\hline Manuscript ID & cjce-2015-0084.R1 \\
\hline Manuscript Type: & Article \\
\hline Date Submitted by the Author: & 11 -Aug-2015 \\
\hline Complete List of Authors: & $\begin{array}{l}\text { Hassan, Rusul; Suncor, } \\
\text { Mohareb, Magdi; University of Ottawa, Civil Engineering }\end{array}$ \\
\hline Keyword: & $\begin{array}{l}\text { structure - steel < Struct. Eng. \& Constr. Mate, structural engineering < } \\
\text { Computer Applications, vibrations and stability < Engineering Mechanics, } \\
\text { code formul \& safe cons < Struct. Eng. \& Constr.Mate }\end{array}$ \\
\hline \multicolumn{2}{|c}{} \\
\hline
\end{tabular}




\title{
Distortional Lateral Torsional Buckling for Simply Supported Beams with
}

\section{Web Cleats}

\author{
by Rusul Hassan ${ }^{(1)}$ and Magdi Mohareb ${ }^{(2)}$ \\ ${ }^{(1)}$ Suncor Energy Inc., Fort McMurray, AB, T9H 3E3 \\ ${ }^{(2)}$ University of Ottawa, Ottawa, ON, K1N 6N5
}

\section{Abstract}

Critical moment expressions for steel beams based on elastic lateral torsional buckling as given in classical solutions and present standard provisions are based on assumed fully restrained support conditions and simplifying kinematic assumptions which neglect distortional effects. The present study carefully examines the applicability of such assumptions in the case of simply supported beams with double angle cleat connections. A parametric study based on shell finite element analysis is first conducted on steel beams and end connection details of common configurations. It is shown that, throughout buckling, (a) typical cleat angles provide only partial twist restraints to beam ends, and (b) beams undergo some distortion not captured in the classical solution, both phenomena resulting in a reduced critical moment capacity. The associated critical moments are then quantified by applying three modifiers to existing design provisions: (1) a partial twist restraint factor based on a potential energy formulation, (2) a distortional coefficient based on regression analysis of FEA results, and (3) a standard dependent factor which ensures consistency in buckling predictions based on various design standards. The modified procedure is shown to yield critical moments that are consistent with those based on FEA buckling simulations. Comparative design examples are then provided to illustrate the merits and applicability of the proposed procedure in practical design situations. 


\section{Keywords}

Distortional lateral torsional buckling, partial twist restraints, web cleat angles, finite element analysis, principle of stationary total potential energy

\section{Introduction}

Web cleats are commonly used as simple shear connections in steel construction. They consist of double angles of equal size (Figure 1). One leg of the cleat angle is connected to the beam while the other is typically connected to a column (not shown) either through bolts or fillet welds. When the beam span is long and when it is laterally unsupported between both ends, its flexural resistance is typically governed by lateral torsional buckling (LTB). Figure 2 depicts the beam cross section prior to loading, at the onset of buckling, and after LTB has occurred. The applied loads cause the cross-section to deflect vertically by a displacement $v$. When moments attain a critical magnitude, the beam reaches a point of instability at which it undergoes lateral translation $u$ defined at the shear centre and a twist angle $\theta$. At this point, the beam is unable to resist additional forces. In Fig. 2, in going from the initial position to the buckled configuration, the section is assumed to act as a rigid disk within its own plane, in line with the Vlasov first assumption (Vlasov 1961). Under the Vlasov classical lateral torsional buckling theory, the section's final configuration is fully characterized by only three displacements $v, u$, and $\theta$ leading to considerable simplifications in the solution. For beams with doubly symmetric wide flange cross-sections, steel design standards adopt, as a starting point, the classical closed form expression for the critical moment $M_{u}$ of a simply supported beam under uniform moments given by

[1] $M_{u}=\frac{\pi}{L} \sqrt{E I_{y} G J+\left(\frac{\pi E}{L}\right)^{2} I_{y} C_{w}}$

in which $L$ is the unbraced segment, $E$ is the elasticity modulus, $I_{y}$ is the weak axis moment of inertia, $G$ is the shear modulus, $J$ is the Saint-Venant torsional constant, and $C_{w}$ is the warping constant. The critical moment expression is derived under the simply supported assumptions $u=u^{\prime \prime}=\theta=\theta^{\prime \prime}=0$ at $z=0, L$. Whether the 
conditions $u(0)=\theta(0)=u(L)=\theta(L)=0$ are fully realized in a beam with web cleat connections is unclear and is one of the motives of the present study.

To generalize the solution for practical loading cases, various standards start with the uniform moment $M_{u}$ as given by Eq. [1] and modify it through a moment gradient factor $C_{s}$ to account for more realistic moment distributions. The nominal critical moment thus takes the form $M_{n}=C_{s} M_{u}$. As a matter of notation, subscript $s$ takes the values $C A N, A I S C, A U S$, or $E U R$ to respectively denote the Canadian, American, and Australian standards, and the Eurocode guide. Factors $C_{s}$ are based on bending moment values at sampling points within the span. In the Canadian standards CAN/CSA S16-14, the moment gradient factor takes the form

[2] $C_{C A N}=\frac{4 M_{\max }}{\sqrt{M_{\max }{ }^{2}+4 M_{A}{ }^{2}+7 M_{B}{ }^{2}+4 M_{C}^{2}}} \leq 2.5$

where $M_{A}, M_{B}$, and $M_{C}$ are the bending moments at quarter-span, mid-span, and three-quarter span points within the unbraced segment, and $M_{\max }$ is the maximum bending moment within the unbraced span. Under the ANSI/AISC (2010), it takes the form

[3] $C_{\text {AISC }}=\frac{12.5\left|M_{\max }\right|}{2.5\left|M_{\max }\right|+3\left|M_{A}\right|+4\left|M_{B}\right|+3\left|M_{C}\right|} \leq 3.0$

while in the Australian standards AS 4100 (1998), it takes the form

[4] $C_{A U S}=\frac{1.7 M_{\max }}{\sqrt{M_{A}^{2}+M_{B}^{2}+M_{C}^{2}}} \leq 2.5$

The Euro-code guide (EN-1993-1-1) tabulates various moment gradient coefficients depending on the load distribution. For a point load acting at mid-span, it takes the value $C_{E U R}=1.365$. Strictly speaking, when a beam buckles, its cross section does not act as a rigid disk as implied in the Vlasov assumption (Fig. 1c) but is susceptible to distortional deformation (Fig. 1d). Distortion is characterized by web deformation within the plane of the crosssection causing the top flange to twist by an angle $\theta_{T}$ which is generally differs from that of the bottom flange $\theta_{B}$ leading to a lower LTB moment than predicted by the classical solution (based on the rigid disk assumption as depicted in Fig. 1c). In cold formed steel members, given the high slenderness of their cross-sectional elements, 
distortional LTB has received comparatively more attention (AISI S100-07 2007) than rolled sections with relatively thick webs which are generally thought as unsusceptible to distortional effects. This hypothesis is carefully examined in the present study through a systematic finite element analysis (FEA) parametric study.

Fig. 1 (a) Web cleat connection at a beam end (b) LTB under the Vlasov Assumption, (c) Classical LTB and (d) Distortional LTB

\section{Literature Review}

A comparative methodological review on distortional buckling formulations is provided in Pezeshky and Mohareb (2014a). Rajasekaran and Murray (1973) and Johnson and Will (1974) developed solutions to predict the distortional buckling capacity of wide flange members. Using the finite strip method, Hancock (1978) showed that typical beams undergo web distortion while flanges remain undistorted. Hancock et al. (1980) developed a distortional buckling solution for simply supported wide flange beam-columns under uniform moments. Bradford and Trahair (1981) developed a finite element buckling solution which captures distortional effects. Bradford and Trahair (1982) investigated moment gradient effects in lipped channels. Using a plate buckling distortional solution, Roberts and Jhita (1983) developed the buckling characteristic equation of wide flange sections. In a series of studies, Bradford developed distortional lateral buckling solutions for mono-symmetric cross-sections (Bradford 1985), inelastic buckling of I-beams (Bradford 1986), mono-symmetric I-beams with continuous elastic lateral restrains (Bradford, 1988), beam columns (Bradford, 1990), cantilevers (Bradford 1992a), investigated the effects of end conditions, rotational and translational restraints for I-beams (Bradford 1992b), and beams laterally restrained at one flange (Bradford and Ronagh, 1997). Wang et al. (1991) provided a comparison of distortional and non-distortional buckling for mono-symmetric simply supported beam columns. Hughes and Ma (1996a) developed a distortional buckling solution for simply supported monosymmetric I-beams under point loads, and distributed transverse loads with unequal end moments (Ma and Hughes 1996). Dekker and Kemp (1998) developed a distortional buckling solution for I-Beams in which they idealized the flanges as translational and rotational springs, while treating the web as an elastic plate. Pi and Trahair (2000) developed effective torsional and warping rigidities for I-Beams which incorporate distortional effects. Using a Fourier series solution, Ng and Ronagh (2004) developed a distortional buckling solution for I-Beams which incorporates the effect of elastic restraints and load offset from the shear centre. Poon and Ronagh (2004) developed a distortional buckling model which idealizes the web lateral 
displacement using a fifth order polynomial. Using shell analysis within the FEA program BASP, Dowswell (2004) conducted a parametric distortional lateral torsional buckling of wide flange cantilevers. Based on shell analysis, Samanta and Kumar (2006) conducted a parametric distortional buckling analysis for simply supported monosymmetric I beams. Vrcelj and Bradford (2006) investigated the distortional buckling for I-beams with the tension flange seated on a support. Zirakian and Showkati (2007) experimentally verified the occurrence of distortion in the buckled configuration in beams. Within the constrained finite strip method, Ádány and Schafer (2008) devised a mode decomposition technique to extract distortional buckling moments. Samanta and Kumar (2008) developed a parametric study on the distortional buckling capacity of cantilevers with mono-symmetric Isections in which they studied the effect of load position and bracing height. Using the finite strip method, Zirakian (2008) studied the distortional buckling of I-beams and concluded that AISC recommendations for distortional lateral torsional buckling are conservative. By assuming a quadratic distribution of the web lateral displacement, Chen and Ye (2010) developed a distortional buckling solution for I-beams and applied it for simply supported beams with a single restrained flange. Using the effective section properties developed by Pi and Trahair (2000), Kalkan and Buyukkaragoz (2012) quantified the elastic and inelastic distortional critical moments for beams and compared their results to AISC (2005), Eurocode 3 (2003) and AS 4100 (1998) recommendations. Most recently, Pezeshky and Mohareb (2015) developed beam finite element solutions which capture distortional effects. A feature common to the above studies is that member ends were assumed either fully fixed, pinned, or entirely free. Within this context, the present study aims at determining the distortional lateral torsional buckling of beams with more realistic boundary conditions representative of typical end connections for beams.

\section{Objectives}

The present study investigates the elastic distortional LTB resistance for beams with realistic end connections consisting of double web cleats welded at the toe to a supporting column and bolted to beam web (Fig. 1a). Beam sizes investigated are the W150, W200, and W310 series from the Canadian Institute of Steel Construction tables (CISC 2010). Members are subjected to mid-span point load acting at section mid-height. The study aims to (a) quantify the reduction in critical moments due to distortional effects, (b) assess whether the idealized boundary

conditions $u(0)=\theta(0)=u(L)=\theta(L)=0$ forming the basis of design procedures in standards are realized for the web cleat connection details, and (c) propose design rules which account for any deviations from idealized 
conditions observed under (a) or (b). The proposed design rules are intended for the design of beams for laterally unsupported beams bent about their strong axis commonly encountered in open steel framework in industrial structures, refineries, petrochemical plants, power plants, pipe racks, etc.

\section{Finite Element Analysis}

\subsection{Selection of Parametric Runs}

A total of 42 runs were conducted. All W150 and W200 were analyzed. For the W310 series sections W310x21 through W310x107 were investigated. For W310 sections, since sections heavier than W310x107 would predominantly be used as columns rather than beams, they were discarded from the present study which focuses on flexural members. For the most part, beam spans were chosen to lie near the threshold of inelastic and elastic LTB based on CAN/CSA S16-2014 standards predictions. As such, for Class 1 and 2 sections, span $L$ was calculated by equating the inelastic LTB moment $M_{\text {in }}$ to $0.67 M_{p}$ and solving for the span $L$ yielding

[5] $L=\frac{\pi C_{C A N} E \sqrt{2 I_{y} C_{w}}}{\sqrt{-\left(G J E I_{y}\right) C_{C A N}{ }^{2}+\sqrt{\left(G J E I_{y}\right)^{2} C_{C A N}{ }^{4}+1.76\left(M_{p}\right)^{2} E^{2} I_{y} C_{w}}}} \leq 12 m$

For Class 3 sections, a similar equation is used while replacing of the plastic moment $M_{p}$ with the yield moment $M_{y}$. Beams with spans less than $L$ would fail by inelastic LTB, or yielding. In Eq. [5], the moment gradient factor was based on Eq. [2] which yielded $C_{C A N}=1.265$ for the mid-span point load considered. Span $L$ was then rounded up (to ensure that the member buckles elastically) to the nearest $100 \mathrm{~mm}$. An upper limit of $12 \mathrm{~m}$ was enforced in Eq. [5] since longer spans would likely involve splicing and would thus be infrequently encountered in practice. In 36 of the 42 runs, double cleat angles with L89x89x6.4 cross-sections were adopted while in the remaining six runs (runs 8a-d and 16a-b) the cleat angle thickness was varied to control the end twist restraints provided to the beam. Heights $h_{c}$ (Fig. 1a) for cleat angles were varied with beam depth. Design aids provided in CISC (2010) were used as guidelines for selecting the cleat angle height and bolt spacing. 


\subsection{Finite Element Model}

A buckling eigenvalue analysis was conducted to extract the buckling loads and mode shapes. Steel was modelled as an elastic isotropic material with an elasticity modulus $E=200,000 M P a$ and a Poisson's ratio $\mu=0.3$. The four-noded quadrilateral stress-displacement S4R shell element with reduced integration and a large-strain formulation was used to mesh the beam. A mesh sensitivity analysis for several W310 sections was conducted and resulted in element size of approximately $8 m m \times 8 m m$. A typical mesh is shown in Fig. 2a. To simulate the boundary conditions of the welds connecting the cleat angle to the supporting column (Fig. 2a), nodal translations at the toes of the cleat angles were restrained along the entire length of the angle, along the $x, y$, and $z$ directions. The flexibility of the supporting columns was neglected.

Bolts were simulated through the use of the "Discrete Fasteners" feature in Abaqus (Fig. 2b, c). The modeling process involves identifying the surfaces to be fastened. In the present problem, these would be the beam web and both cleat angles. This is then followed by specifying the number of points to be fastened (i.e., the bolts), their coordinates, and radius of influence (i.e., bolt radius). The coupling type must then be specified. For the purpose of this study the "Structural Coupling" feature was chosen. Under this feature, the translational and rotational degrees of freedom for each fastening point were coupled to the translational and the rotational degrees of freedom of the group of coupled nodes on each of the fastened surfaces. In the present study, the degrees of freedom of the nodes within the specified radius of influence on the web cleats were coupled to those of the nodes within the radius of influence on the beam web. It is noted that the above procedure is distinct from node to node coupling. Rather, it is a weighted average of the rotations and translations of the nodes within the radius of influence on the beam is taken, and all the nodes within the radius of influence on the web cleats are coupled to that weighted average. No attempt was made to model the contact between the bolts and holes as such a model would have been possible in a nonlinear load-deformation analysis type rather than the eigenvalue analysis type sought in the present study.

Fig. 2 - Boundary Conditions and Abaqus model representation of (a) Radius of influence and (b) Fasteners In the FEA model, in order to apply a mid-span load $P$ at web mid-height while avoiding localized effects, the applied load was simulated by applying two equal point loads $P / 2$ acting at the top and bottom web to flange junctions at the beam mid-span. 


\section{Finite Element Results}

\subsection{FEA-predicted Moment Gradient Factor}

For the FEA runs, Table 1 lists the section designation, beam span $L$, cleat angle designation, and cleat angle height $h_{c}$ in Columns 2-5. Column 6 provides the twisting stiffness $R$ provided by the web cleat connection to the supported beam as given by

[6] $R=\frac{G J_{c}}{L_{c}}=\frac{2 G h_{c} t_{c}^{3}}{3 L_{c}}$

where $L_{c}$ is the cleat span from the face of the supporting column to the bolt line (in all runs $L_{c}$ was taken as 52.6 $\mathrm{mm}$ ) and $J_{c}=h_{c} t_{c}^{3} / 3$ is the Saint-Venant torsional constant for a single leg (of thickness $t_{c}$ ) adjacent to the web. Coefficient 2 in Eq. 6 accounts for the presence of two cleat angles. Column 7 provides the relative twist stiffness defined as $\alpha=\left(G J / L+\pi^{2} E C_{w} / L^{3}\right) / R$. It represents the torsional stiffness of the beam (including the SaintVenant and warping torsional contributions) to that of the end elastic rotational restraint $R$ provided by the cleat angle.

Column 8 provides the non-distortional critical moment $M_{u}$ (as obtained from Eq. 1) for the hypothetical case of uniform moments, based on the idealized boundary conditions $u=u^{\prime \prime}=\theta=\theta^{\prime \prime}=0$ at $z=0, L$ while Column 9 provides the critical distortional lateral torsional moment $M_{F E A}$ as predicted by the FEA which accounts for (a) the non-uniform moment effect and (b) the partial end restraints as provided by the cleat angles. Column 10 provides the dimensionless ratio $M_{F E A} / M_{u}$ which accounts for moment gradient, distortional effects, and partial fixity effects. Column 11 provides the ratio of the angle of twist $\theta_{E}$ at the beam end to that at mid-span $\theta_{M}$ as predicted by the FEA. Strictly speaking, in a distorted section, each area segment of a cross-section undergoes a distinct angle of twist, i.e., the definition of the angle of twist of a cross-section is non-unique. Pezeshky and Mohareb (2014b) proposed an area-averaged angle of twist indicator as a measure to characterize the twist of a distorted cross section and the area-averaged standard deviation of the angle of twist to characterize its distortion. In the present study, we adopt the following definitions for the end angle of twist 


$$
\begin{aligned}
& \theta_{E}=\left(u_{t, E}-u_{b, E}\right) / h \\
& \theta_{M}=\left(u_{t, M}-u_{b, M}\right) / h
\end{aligned}
$$

in which $u_{t, E}, u_{b, E}$ are the lateral displacements at beam end at the top and bottom flange to web junctions, $u_{t, M}, u_{b, M}$ are the mid-span lateral displacements at the top and bottom flange to web junction and $h$ is the section height as measured between flange mid-surfaces. A ratio $\theta_{E} / \theta_{M}$ approaching zero indicates negligible end twist and suggests the classical boundary conditions $\theta(0)=\theta(L)=0$ are approached.

The factor $M_{F E A} / M_{u}$ (Column 10) is observed to range from 1.159 to 1.401 , with an average of 1.281 . This compares to moment gradients of 1.265 (based CAN/CSA S16-14), 1.316 (based on ANSI/AISC 360-10), 1.365 based onEN 1993-1-1), and 1.388 (based on AS 4100-1998). On average, the ratio $M_{F E A} / M_{u}$ is in reasonable agreement with moment gradients based on standards. However the scatter observed suggests an inconsistent level of safety in standard procedures. Figure 3 a provides a comparison between the $M_{F E A} / M_{u}$ ratio obtained by the present study to the moment gradient factors based on various standards. Of the 42 runs, standard provisions were observed to overestimate the critical moments in 20 cases for the Canadian Standards, 33 cases for the American standards, 39 cases for the Eurocode Guide, and 41 cases for the Australian standards. The large number of unconservative predictions is indicative of the fact that partial fixity conditions provided by cleat angles and distortional effects are not captured in present design provisions.

Fig. 3 - FEA results (a) $M_{F E A} / M_{u}$ ratio (b) lateral displacement profile at beam ends

\section{Table 1 Results of the parametric study}

\subsection{Assessing the End Lateral Fixity Condition}

In the derivation of the classical LTB solution, it is assumed that beam ends do not experience lateral displacements. To verify this assumption, dimensionless end lateral displacement profiles for runs $16,16 \mathrm{a}$, and $16 \mathrm{~b}$ for the W200x100 beams are plotted in Fig. 3b. All displacements are normalized with respect to the mid-span displacement at the top flange, which corresponds to the largest displacement. It is observed that, irrespective of the twisting stiffness provided by the cleat angles, the web mid-height experiences a negligible lateral displacement of 
the order of $0.22 \%$ of the maximum lateral displacement. As such, the assumption of zero lateral displacement at the beams ends adopted in the classical solution appears to be vindicated.

\subsection{Effect of End Twist Partial Fixity Condition}

The classical LTB solution given by Eq. [1] is based on the assumption that beam ends are fully restrained from twisting. Results in Column 11 of Table 1 show some twist deformation, suggesting that the classical assumption may be inaccurate in the present problem. The smallest FEA-predicted moment gradient in Column 10 corresponds to Run 16 for the W200x100 beam (the heaviest section investigated) with the default cleat angles 2-L89x89x6.4. This case happens also to correspond to the largest end twist to the mid-span twist ratio of $\theta_{E} / \theta_{M}=0.1643$ (Column 10). This high $\theta_{E} / \theta_{M}$ ratio suggests that the default cleat angle size (L89x89x6.4, with a twisting stiffness $R=38.3 \mathrm{kNm} / \mathrm{rad}$ ) may not be fully effective in restraining the end twist deformation. To further investigate this hypothesis, two additional FEA runs were conducted with thicker cleat angles (runs 16a,b) with L89x89x9.5 cleat angles $(R=359 \mathrm{kNm} / \mathrm{rad})$ and L89x89x13 $(R=125 \mathrm{kNm} / \mathrm{rad})$. Indeed, an increase in the twist resistance provided by the cleats corresponded to an increase in the FEA-predicted moment gradient from 1.159 for the L89x89x6.4 cleat angle, to 1.240 for the L89x89x9.5, to 1.301 for the L89x89x13. Also, the corresponding $\theta_{E} / \theta_{M}$ ratio was observed to decrease from 0.1643 to 0.0859 , to 0.0565 , respectively. A similar observation can be made by comparing the outcome of runs $8 \mathrm{a}-\mathrm{d}$, where the W310x52 beam cross-section and span of $5700 \mathrm{~mm}$ were kept constant, while the thickness of the cleat angles was increased from $6.4 \mathrm{~mm}$ to $13 \mathrm{~mm}$. An increase in the partial twist restraint provided is thus concluded to reduce the angle of twist at beam ends and is associated with an increase in the LTB capacity of the system.

\subsection{Effect of Distortion}

The previous section suggests that the variability in the FEA predicted moment to the classical critical moment ratio (Column 10 of Table 1) is attributed to the degree of partial twist restraints provided by cleat angles. It is noted here that the degree of twist restraint is not the sole source in the scatter observed. This is verified by considering the results for run 8c (W310x52 with 2L89x89x8.7) and run 15 (W310x21 with 2L89x89x6.4). Both runs have identical relative twist stiffness ratios $\alpha=0.0451$. Yet, the corresponding FEA predicted critical moment to classical critical moment ratio for run $8 \mathrm{c}$ is 1.262 , a distinctly lower value from the 1.337 ratio for run 15 . The 
reason for the difference becomes apparent when comparing the distorted buckled configurations of both beams (Fig. 4). As depicted, the web for run $8 \mathrm{c}$ undergoes more distortion than that of run 15 . The degree of distortion is thus judged to play an important role in the scatter. A recent study on distortional buckling of beams under uniform moments (Hassan and Mohareb 2012) has shown that distortional effects tend to increase with flange slenderness $b / t$, and aspect ratio $b / h$, as a larger and flange tends to attract more compressive stresses inducing distortion into the supporting flexible web. Both parameters are higher for the W310x52 section. The same study shows that distortional effects increase with web slenderness $h / w$. In this respect, the W310x52 has a lower slenderness. The higher flange slenderness $b / t$ and aspect ratio $b / h$ of the W310x52 section seem to offset the web slenderness effect, resulting into more distortion than the W310x21 section.

\section{Developing Design Coefficients}

\subsection{General}

The classical LTB solution is based on three assumptions: 1) the beam is subject to uniform moment distribution, 2) ideal simply supported conditions, both in the lateral and torsional directions (i.e., the beam is fully restrained against lateral displacement and twist at both ends) and, 3) the beam cross-section exhibits no distortion. Assumption (1) is addressed in various standards through the introduction of moment gradient factor $C_{s}$. Regarding assumption (2), Section 5.2 has revealed that the lateral restraint assumption appears to be valid while Section 5.3 suggested that end twist restraints provided by cleat angles are only partial. Assumption (3) appears to be only approximate given the distorted shapes shown in Fig. 4. Thus, modifications to standard procedures are needed to account for partial twist restraints at the ends and for cross-sectional distortion. Since the nominal elastic LTB resistance in various standards takes the form $M_{n}=C_{s} M_{u}$, which does not explicitly address distortional effects and partial end twist restraints, but solely incorporates the effect of moment gradient through $C_{s}$, it is proposed to apply three additional coefficients $C_{R}, D$, and $S_{s}$ to the standard design equation, i.e.,

[8] $M_{c r}=S_{s} D C_{R}\left(C_{s} M_{u}\right)$

in which Coefficient $C_{R}$ accounts for the partial twist restraint provided by the cleat, Coefficient $D$ accounts for distortional effects as determined by FEA results, and Coefficient $S_{s}$ is a standard constant which ensures that the 
critical moment predictions $M_{c r}$ are consistent with those based on the code predictions (i.e., while $C_{s} M_{u}$ presently varies from one standard to another, given the slightly different expressions for the moment gradient $C_{s}$, the present study will target a constant product $M_{c r}=S_{s} C_{s} M_{u}$ to yield universal predictions among various standards). Sections 6.2-6.4 develop expressions for the sought coefficients $C_{R}, D$, and $S_{s}$, respectively.

\subsection{Formulating Coefficient for Partial Twist Restraint}

In this section, we consider the beam ends to be laterally restrained (as observed in Section 5.2) but partially restrained against twist (as concluded under Section 5.3) through a rotational spring of constant $R$ at each end. The total potential energy $\pi_{p}$ of the system is given by

[9] $\pi_{p}=U_{b}+U_{R}+V$

where $U_{b}$ is the internal strain energy stored within the beam, $U_{R}$ is the energy stored within the cleat angles (treated as rotational springs), and $V$ is the load potential energy gained by the moments as the beam undergoes LTB. The above energy contributions take the forms (e.g., Trahair 1993)

$[10] \mathrm{a}-\mathrm{c}$

$$
\begin{aligned}
& U_{b}=\frac{1}{2} \int_{0}^{L} E I_{y} u(z)^{\prime \prime 2} d z+\frac{1}{2} \int_{0}^{L} G J \theta(z)^{\prime 2} d z+\frac{1}{2} \int_{0}^{L} E C_{w} \theta(z)^{\prime \prime 2} d z, \\
& U_{R}=\frac{R}{2}[\theta(0)]^{2}+\frac{R}{2}[\theta(L)]^{2},
\end{aligned}
$$

The mode shapes as observed in the FEA provide a basis to assume displacement functions that are more realistic than those based on the classical solution. Approximate functions for lateral displacement $(u)$ and angle of twist $(\theta)$ which meet all essential and natural boundary conditions are

$[11] \mathrm{a}-\mathrm{b}$

$$
u(z)=A \sin \left(\frac{\pi z}{L}\right), \quad \theta(z)=B+C \sin \left(\frac{\pi z}{L}\right)
$$

The introduction of constant $B$ in Eq. [11]b is consistent with the fact that in the FEA, end rotations were observed to be non-zero, in contrast to the classical solution. For a simply supported beam with span $L$ under mid-span loading, the bending moment $M(z)$ can be expressed in terms of the peak bending moments at mid-span $M_{0}$ as 


$$
M(z)=\left\{\begin{array}{cc}
2(z / L) M_{0} & 0 \leq z \leq L / 2 \\
2(1-z / L) M_{0} & L / 2 \leq z \leq L
\end{array}\right.
$$

From Eqs. [10] and [11], by substituting into Eq. [9] and evoking the stationary conditions $\partial A / \partial \pi_{p}=\partial B / \partial \pi_{p}=\partial C / \partial \pi_{p}=0$, one obtains the neutral stability condition

[13]

$$
\left[\begin{array}{ccc}
\frac{\pi^{4} E I_{y}}{2 L^{3}} & \frac{-4 M_{0}}{L} & -\frac{M_{0}}{L}\left(\frac{\pi^{2}}{4}+1\right) \\
\frac{-4 M_{0}}{L} & 2 R & 0 \\
-\frac{M_{0}}{L}\left(\frac{\pi^{2}}{4}+1\right) & 0 & \frac{1}{2}\left(\frac{\pi^{2} G J}{L}+\frac{\pi^{4} E C_{w}}{L^{3}}\right)
\end{array}\right]\left\{\begin{array}{l}
A \\
B \\
C
\end{array}\right\}=\left\{\begin{array}{l}
0 \\
0 \\
0
\end{array}\right\}
$$

By setting the determinant of the matrix in Eq. [13] to zero, one recovers the critical moment expression

$$
\text { [14] } M_{0}=\sqrt{\frac{\left(\pi^{4} E I_{y} / 2 L\right)\left(\pi^{2} G J / L+\pi^{4} E C_{w} / L^{3}\right)}{2\left(\pi^{2} / 4+1\right)^{2}+(8 / R)\left(\pi^{2} G J / L+\pi^{4} E C_{w} / L^{3}\right)}}
$$

Taking the limit of the critical moment $M_{0}$ as the rotational spring stiffness $R$ tends to infinity, one obtains the critical moment $M_{\infty}$ for the idealized case where both ends are fully restrained from twisting as

[15] $M_{\infty}=\lim _{R \rightarrow \infty} M_{0}=\frac{\pi^{2}}{2\left(\pi^{2} / 4+1\right)}\left(\frac{\pi}{L}\right) \sqrt{\left(E I_{y} G J+\left(\frac{\pi E}{L}\right)^{2} I_{y} C_{w}\right)}=\frac{\pi^{2}}{2\left(\pi^{2} / 4+1\right)} M_{u} \approx 1.423 M_{u}$

As expected, when the ends of a beam are fully restrained, the critical moment obtained corresponds to a moment gradient factor $\left(C_{E}=\pi^{2} / 2\left(\pi^{2} / 4+1\right)=1.423\right.$ ) multiplied by the uniform critical moment $M_{u}$, in a manner similar to expressions in various standards. The energy predicted moment gradient factor $C_{E}=1.423$ derived is slightly larger than that provided in standards since: a) the assumed displacement and twisting functions postulated in Eqs. [11] are approximate, and b) the moment gradient coefficients based on quarter point formulas in standards are approximate. Improved moment gradient predictions can be obtained by postulating displacement functions involving more degrees of freedom, resulting in a larger size eigen-value problem. Alternatively, FEA buckling analysis can be used to evaluate the moment gradients numerically using thin-walled beam models. Unlike shell models, beam models supress distortional effects. Three problems were investigated a W410x39 with a span of 
$4.5 \mathrm{~m}$, a W410x39 with a span of 8.0m, and a W310x53 with a span of 5.7m. For each problem, two Eigen FEA solutions were conducted: (1) the element of Barsoum and Ghallagher (1970) and the Thin walled beam element B310S element in Abaqus. A mesh study was conducted in each case and the number of elements needed for convergence was determined ( 8 elements for the former solution and 40 for the later). The critical moments obtained were divided by the uniform critical moment given by the classical solution. In all cases, the moment gradient factors obtained ranged between 1.362 and 1.363. These values are in close agreement with the 1.365 value reported in the Eurocode. Since the Eurocode provides specific values is for the given load patterns (mid-span load) as opposed to a generic quarter point formula, it yields accurate moment gradient factors. In contrast, the moment quarter point formulas in other standards, which are intended for general moment distributions, yield only approximate results for the present problem. The Canadian and American moment gradient factor formulas values of 1.265 and 1.316 err on the conservative side while the Australian moment gradient factor of 1.388 is marginally unconservative. In the present study, we will retain the simplicity of the formulation provided in Eq. 14 while incorporating more accurate moment gradient expressions subsequently. Equation [14] can be expressed as

[16]a-b $M_{0}=C_{R}\left(C_{E} M_{u}\right), \quad C_{R}=\sqrt{\frac{1}{1+1.642 \alpha}}$

where $C_{R}$ can be thought of as a reduction factor to be applied to the energy predicted critical moment $C_{E} M_{u}$ based on infinite twist resistance, and is intended to account for the partial twisting restraint. In Eq. [16]b, we recall that the relative twist stiffness $\alpha=\left(G J / L+\pi^{2} E C_{w} / L^{3}\right) / R$ represents the torsional stiffness of the beam (consisting of the sum of the Saint-Venant and warping torsional stiffness) to that of the end elastic rotational restraint $R$ provided by the cleat angles.

\subsection{Formulating Distortional Coefficient}

For a given FEA run $i$, given the critical moments $M_{F E A}$ as predicted from the FEA, the energy-based moment gradient factor $C_{E}=1.423$, and the partial twist restraint coefficient from Eq. 16b, distortional coefficient $\left(D_{F E A}\right)_{i}$ can be determined from

[17] $\left(D_{F E A}\right)_{i}=\left(\frac{M_{F E A}}{C_{R} C_{E} M_{u}}\right)_{i}$ 
The results for all runs are compiled in Table 2. As expected, distortional coefficient $\left(D_{F E A}\right)_{i}$ is less than unity in all cases, except for run $16 \mathrm{~b}$, which involves a thick web connected to a thick cleat angle. It is reasoned that both thick components are able to transfer small negative moments at beam ends, causing a slight reduction in the positive moments at mid-span. The associated reduction in compressive stresses at mid-span reduces the destabilizing effect $V$ as determined by Eq. 10a, and causes a slight increase in the predicted critical moment compared to the hypothetical case of zero end moments as implied by Eq. 12, and hence the higher $\left(D_{F E A}\right)_{i}$.

In design situations, it is impractical to conduct FEA to quantify distortional effects. Thus, the present section develops an approximate expression to quantify critical moment reductions due to distortion. The distortional coefficient sought is based on regression analysis on the results obtained in Table 2. As discussed under Section 5.4, the distortional LTB moments to classical critical moment (excluding distortional effect) depend on $w / h, t / b$, $b / h$ (Hassan and Mohareb 2012) for beams under linear moment gradients. We extend the observation to the present problem by postulating the following expression for the distortional coefficient

[18] $D=a_{1}+a_{2}\left(\frac{w}{h}\right)_{i}+a_{3}\left(\frac{L}{h}\right)_{i}+a_{4}\left(\frac{b}{h}\right)+a_{5}\left(\frac{t}{b}\right)$

in which constants $a_{1}$ through $a_{5}$ are obtained by minimizing the sum of the squares of errors $\sum_{i}\left[D_{F E A i}-D_{i}\right]^{2}$ yielding

[19] $D=1.00+3.32\left(\frac{w}{h}\right)-1.27 \times 10^{-3}\left(\frac{L}{h}\right)-4.92 \times 10^{-2}\left(\frac{b}{h}\right)-1.20\left(\frac{t}{b}\right) \leq 1.0$

where the ceiling value of 1.0 is consistent with the fact that distortional effects cannot increase the critical moment capacity based on physical grounds. Equation 19 is observed to give results within $-4.5 \%$ to $3.6 \%$ of those based on $D_{F E A}$, with a standard deviation of $1.9 \%$. Equation 16 a and 19 can be combined to predict the distortional moment, i.e.,

[20] $M_{d}=D_{F E A} M_{0} \approx D M_{0}=D\left(C_{R} C_{E} M_{u}\right)$

Table 2 Comparison of buckling solutions and development of design coefficients 


\subsection{Standard Consistency Coefficient}

The distortional moments given in Eq. [20] are universal (i.e., non-standard dependent). However, given that the energy based moment gradient factor $C_{E}$ is larger than that based on standards (i.e., $C_{S}$ ), Eq. [16]a will tend to overestimate the critical moments for the case of infinite end twist stiffness (i.e., $C_{R}=1.0$ ) compared to the nominal moment capacity as predicted by standard provisions. Thus, to ensure consistency between the predictions of Eq. [20] and those based on standard provisions, we introduce a standard dependent consistency coefficient $S_{s}=C_{E} / C_{s}$ such that the distortional critical moment $M_{c r}$ can be related to $C_{S}$ (instead of $C_{E}$ ) as follows

$$
M_{c r}=D\left(C_{R} C_{E} M_{u}\right)=\left(\frac{C_{E}}{C_{s}}\right) D C_{R} C_{s} M_{u}=S_{s} D C_{R} C_{s} M_{u}
$$

which reverts to the format proposed in Eq. [8]. The consistency coefficients $S_{s}$ are $S_{C A N}=C_{E} / C_{C A N}=1.423 / 1.265=1.125$ for the Canadian Standards, $S_{\text {AISC }}=C_{E} / C_{\text {AISC }}=1.423 / 1.316$ $=1.081$ for the American Standards, $S_{E U R}=C_{E} / C_{E U R}=1.423 / 1.365=1.042$ for the Eurocode, and $S_{A U S}=C_{E} / C_{A U S}=1.423 / 1.388=1.025$ for the Australian Standards.

In Eq. [21], we recapitulate that the last two terms $C_{s} M_{u}$ represent the critical moment including moment gradient

effects as predicted by applicable standards, $C_{R}$ is a modifier introduced in Eq. [16]b which depends upon the degree of twist restraint provided by end cleats, $D$ is a distortional modifier provided in Eq. [19] which depends on the geometric parameters of the cross-section and the span, and $S_{s}$ is a standard dependent constant.

\section{Design Considerations for Inelastic Lateral torsional buckling}

Standard provisions for inelastic lateral torsional buckling depend upon the yield or plastic moment as well as the elastic lateral torsional buckling resistance. While the present study has focused solely on improving means of prediction of the elastic lateral torsional buckling resistance, it did not attempt to verify/change the inelastic lateral torsional buckling equations to account for factors such inelastic material behavior, initial imperfections, and residual stresses. The authors nevertheless recommend the use of the improved critical moments obtained in the present study with existing inelastic lateral torsional buckling provisions in standards. The proposed approach is consistent with the method of design by advanced analysis recognized in the Australian standards (AS 4100-98) which allows the designer first to determine the elastic critical moment through a buckling eigenvalue analysis (in 
this respect, the present study approximately predicts such critical moments through various coefficients derived), and then use the elastic critical moments in conjunction with standard provisions for inelastic buckling to account for inelastic effects, residual stresses, and initial imperfections. Such a concept was also recommended for the inelastic design of portal frames for inelastic lateral stability (Zinoviev and Mohareb 2004).

\section{Design Examples}

\subsection{Example 1}

A beam with a W410x39 cross-section ( $F_{y}=350 M P a$ ) has a span of $4500 \mathrm{~mm}$. The beam is subject to a midspan load and is connected to rigid columns using double cleat angles at both ends. The cleat angles are L76x76x4.8 and are fastened to the beam web through 3-20 mm A325 bolts. The distance between the angle heel to the bolt centerline is $L_{c}=41 \mathrm{~mm}$ while the cleat angle height is $h_{c}=350 \mathrm{~mm}$. It is required to determine the maximum factored load that the beam can withstand. Design checks are to be performed according to present design standards CAN/CSA S16-14, ANSI/AISC 360-10 as well as the design methodology proposed in the present study. Sectional properties are: beam depth $d=399 \mathrm{~mm}$, flange width $b=140 \mathrm{~mm}$, flange thickness $t=8.8 \mathrm{~mm}$, web thickness $w=6.4 \mathrm{~mm}$, Saint-Venant constant $J=110 \times 10^{3} \mathrm{~mm}^{4}$, out-of-plane moment of inertia $I_{y}=4.40 \times 10^{6} \mathrm{~mm}^{4}$, plastic section modulus about the $x$-axis $Z_{x}=610 \times 10^{3} \mathrm{~mm}^{3}$, and warping constant $C_{w}=154 \times 10^{9} \mathrm{~mm}^{6}$. The cleat angles have a thickness $t_{c}=4.8 \mathrm{~mm}$, and a Saint-Venant constant $J_{c}=57.5 \times 10^{3} \mathrm{~mm}^{4}$.

\section{CAN/CSA S16-14 Solution}

The section flange meets Class 2 requirements since $b_{e l} / t=7.95 \leq 170 / \sqrt{F_{y}}=9.092$. Also, the web meets Class 2 requirements since $h / w=399 / 6.4=62.3 \leq 1700 / \sqrt{F_{y}}=90.89$. Hence, the design will be based on the plastic moment resistance $M_{p}=Z_{x} F_{y}=255.5 \mathrm{kNm}$. The elastic LTB moment is $C_{C A N} M_{u}$ in which the moment gradient factor $C_{C A N}$ is calculated based on the quarter point moment gradient equation, yielding the value $C_{C A N}=1.265$ for a beam under mid-span load. The resulting elastic LTB moment is $C_{C A N} M_{u}=C_{C A N} \frac{\pi}{L} \sqrt{G J E I_{y}+\left(\frac{\pi E}{L}\right)^{2} I_{y} C_{w}}=(1.265)(96.3)=121.8 \mathrm{kNm}$ 
Since $C_{C A N} M_{u} \leq 0.67 M_{p}$, the beam capacity is governed by elastic LTB and the factored flexural resistance is given by $M_{r}=\phi C_{C A N} M_{u}=109.6 \mathrm{kNm}$, and the corresponding factored load is then given by $P_{f \max }=4 M_{r} / L=97.4 k N$

\section{ANSI/AIC 360-10 Solution}

Since $b_{e l} / t=7.95 \leq 0.38 \sqrt{E / F_{y}}=9.08$ and $h / w=399 / 6.4=62.3 \leq 3.76 \sqrt{E / F_{y}}=89.9$, ANSI/ AISC 360-10 also predicts compact section classification and the plastic moment resistance is $M_{p}=Z_{x} F_{y}=255.5 \mathrm{kNm}$. The elastic LTB moment is $C_{A I S C} M_{u}$ in which the moment gradient factor $C_{A S I C}$ is calculated based on the quarter point moment gradient equation, yielding the value $C_{A I S C}=1.316$ for a beam under mid-span load. The resulting elastic LTB moment is

$$
C_{A I S C} M_{u}=C_{A I S C} \frac{\pi}{L} \sqrt{G J E I_{y}+\left(\frac{\pi E}{L}\right)^{2} I_{y} C_{w}}=(1.316)(96.3)=126.7 \mathrm{kNm}
$$

Since $C_{A I S C} M_{u} \leq 0.7 M_{p}$, the beam capacity is governed by elastic LTB and the flexural resistance is given by $M_{r}=\phi C_{A I S C} M_{u}=114.1 \mathrm{kNm}$, and the corresponding factored load is then given by $P_{f \max }=4 M_{r} / L=101.4 k N$

\section{Proposed Solution}

The above solutions do not account for partial twist restraints provided by the cleat angles, nor do they account for distortional effects. In contrast, the proposed design methodology accounts for these effects as described below. To determine the partial twist restraint coefficient $C_{R}$, the twisting stiffness are determined for cleat angles, i.e., $R=G J_{c} / L_{c}=2 G\left(h_{c} t_{c}^{3} / 3\right) / L_{c}=48.4 \mathrm{kNm} / \mathrm{rad}$ and the corresponding twist stiffness dimensionless ratio is $\alpha=(1 / R)\left(G J / L+\pi^{2} E C_{w} / L^{3}\right)=0.1081 \quad$ yielding $\quad$ a $\quad$ reduction $\quad C_{R} \quad$ value $\quad$ of $C_{R}=\sqrt{1 /(1+1.642 \alpha)}=0.922$. This signifies that since the twist restraint of the web cleat connection is only partial, a reduction factor of $92.2 \%$ needs to be applied to the critical moment as determined based on an idealized infinitely rigid twist connection. The factor accounting for reduction due to distortion, $D$ is then determined 
from $D=1.00+3.32(w / h)-1.27 \times 10^{-3}(L / h)-4.92 \times 10^{-2}(b / h)-1.20(t / b)=0.947 . \quad$ This $\quad$ result suggests that, in order to account for distortional effects, a factor of 0.947 needs to be applied to the solution provided by standards which does not incorporate distortional effects. The corresponding critical moment is

$$
\begin{aligned}
M_{c r} & =D C_{R}\left(\phi C_{C A N} M_{u}\right) \\
& =(0.947)(0.922)(109.6) \\
& =95.7 \mathrm{kNm}
\end{aligned}
$$

and the corresponding factored load $P_{f \max }$ is then given by $P_{f \max }=4 M_{c r} / L=85.0 \mathrm{kN}$. If consistent results are to be obtained under both standards, the consistency coefficients $S_{s}=1.081$ for ANSI/AISC $360-10$ and $S_{s}=1.125$ for CAN/CSA S16-14 need to be applied to the above solution. The resulting critical moments are then obtained as

ANSI/AISC 360-10

$$
\begin{aligned}
M_{c r} & =D C_{R} S_{s}\left(\phi C_{s} M_{u}\right) \\
& =(0.947)(0.922)(1.081)(114.1) \\
& =107.6 \mathrm{kNm} \\
P_{f \max } & =4 M_{c r} / L=95.7 k N
\end{aligned}
$$

\section{$\underline{\text { CAN/CSA S16-14 }}$}

$$
\begin{aligned}
M_{c r} & =D C_{R} S_{s}\left(\phi C_{s} M_{u}\right) \\
& =(0.947)(0.922)(1.125)(109.6) \\
& =107.6 \mathrm{kNm} \\
P_{f \max } & =4 M_{c r} / L=95.7 \mathrm{kN}
\end{aligned}
$$

\section{Finite Element Solution}

The nominal critical moments based on FEA are found to be $124.1 \mathrm{kNm}$ and the corresponding factored critical load is $111.7 \mathrm{kN}$.

\section{$\underline{\text { Comparison }}$}

Table 3 provides a summary of the moment predictions by various methods. The FEA solution is used in the last column of the table as benchmark solution against which other solutions are assessed. For the given problem, the CAN/CSA S16-14 procedure underestimates the critical moments by 1.9\% while ANSI/AISC 360-10 overestimates them by $2.1 \%$. By disregarding the consistency coefficient, and retaining the partial twist restraint and distortional coefficients, the modified CAN/CSA S16-14 is observed to underestimate the critical moment by $14 \%$ and the modified ANSI/AISC 360-10 by $11 \%$. After incorporating the consistency coefficients, both standards are found to underestimate the capacity of the beams by $3.7 \%$. For the chosen example, present design standards provide predictions in excellent agreement with FEA results. However, since both standards do not involve means to directly 
capture distortional effects nor partial twist restraints at both ends, such agreement with FEA results will not always be attained as illustrated in the following example.

Table 3 Critical moments for a $4.5 \mathrm{~m}$ span W410x39 beam with 2-L76x76x4.8 cleat angles at both ends

It is required to revise the capacity of the beam in Example 1 if the supporting cleat angles are replaced with thicker L76x76x9.5. The twist stiffness of the new cleat angles would increase to $R=375 \mathrm{kNm} / \mathrm{rad}$, and the corresponding results are summarized in Table 4.

As expected, a thicker cleat angle results in a critical moment as determined by FEA that is higher by about $6.3 \%$ compared to that based on the thinner cleat angle (L76x76x4.8). Again, the FEA predicted moments will serve as a basis to assess the quality of other solutions. The beneficial effect of the thicker cleat angles is not captured by present design rules in CAN/CSA S16-14 nor ANSI/AISC 360-10, which result in lower moment resistance ratios of $92.3 \%$ and $96.1 \%$, respectively.

Under the proposed solution, the partial twist restraint coefficient $C_{R}$ is observed to increase from 0.922 to 0.989 , a 7.3\% difference. The proximity of the new value of $C_{R}$ to unity suggests that the thicker cleat angle provides near full twist fixity to beam ends. This increase in $C_{R}$ is associated with a proportional increase in the predicted critical moments. As a result, the modified procedures (which accounts for moment gradient factor, $C_{R}$ and distortional coefficient $D$, but discarding $S_{s}$ ) the $M_{r} / M_{F E A}$ ratios that are found to be nearly identical to those reported for Example 1, i.e., the moment ratios are 0.864 and 0.900 for CAN/CSA S16-14 and ANSI/AISC 360-10, respectively. When the consistency factor is incorporated into the solution, both modified standards are observed to yield predictions in closer agreement with FEA. In both cases, and $M_{r} / M_{F E A}$ moment ratio of 0.972 is achieved, i.e., the proposed modified procedure predicts the FEA solution within $2.8 \%$.

Table 4 Critical moment for a $4.5 \mathrm{~m}$ span W410x39 beam with 2-L76x76x9.5 cleat angles at both ends Example 3:

A $12 \mathrm{~m}$ span beam has a W200x100 cross-section. The beam is subject to a mid-span load and is connected to rigid columns at both ends using L89x89x6.4 double cleat angles. Cleats are fastened to the beam web through 2-20mm A325 bolts. The distance between the angle heel to the bolt centerline is $L_{c}=52.6 \mathrm{~mm}$ while the cleat angle height is $h_{c}=150 \mathrm{~mm}$. It is required to determine the flexural capacity of the beam according to CAN/CSA S16- 
14 standards, the present study, and compare them to that based on FEA. Two steel strengths are to be investigated $F_{y}=400 M P a$, and $F_{y}=480 M P a$

\section{CAN/CSA S16-14 Solution}

For the case of $F_{y}=400 M P a$, the section is found to be Class 2 since $b_{e l} / t=4.43 \leq 170 / \sqrt{F_{y}}$ and $h / w=12.5 \leq 1700 / \sqrt{F_{y}}$. Hence, the design will be based on the plastic moment resistance $M_{p}=Z_{x} F_{y}=460.0 \mathrm{kNm}$. Given the moment gradient $C_{C A N}=1.265$, one obtains $\bar{M}_{u}=C_{C A N} M_{u}=C_{C A N} \frac{\pi}{L} \sqrt{G J E I_{y}+\left(\frac{\pi E}{L}\right)^{2} I_{y} C_{w}}=(1.265)(288.8)=365.3 \mathrm{kNm}=0.79 M_{P}$

Since $\bar{M}_{u} \geq 0.67 M_{p}$, the beam capacity is governed by inelastic LTB, and the factored flexural resistance is $M_{r}=\phi 1.15 M_{p}\left(1-0.28 \frac{M_{p}}{\bar{M}_{u}}\right)=0.90 \times 1.15 \times 460.0\left(1-0.28 \frac{460.0}{365.3}\right)=308.2 k N m \leq M_{p}$

\section{Proposed Modified CAN/CSA Solution}

The twisting stiffness $R$ of the cleat angles is determined as $R=G J_{c} / L_{c}=38.3 \mathrm{kNm} / \mathrm{rad}$ which corresponds to a twist stiffness dimensionless $\alpha=(1 / R)\left[G J / L+\left(\pi^{2} E C_{w} / L^{3}\right)\right]=0.358$ yielding a reduction $C_{R}$ value of $C_{R}=\sqrt{1 /(1+1.642 \alpha)}=0.794$. The distortional coefficient is given by $D=1.00+3.32\left(\frac{w}{h}\right)-1.27 \times 10^{-3}\left(\frac{L}{h}\right)-4.92 \times 10^{-2}\left(\frac{b}{h}\right)-1.20\left(\frac{t}{b}\right)=0.976 \leq 1.0$

The corresponding nominal elastic LTB resistance based on the proposed modifications is $\overline{\bar{M}}_{u}=S_{C S A} D C_{R} C_{C S A} M_{u}=1.125 \times 0.976 \times 0.794 \times 1.265 \times 288.8=318.8 \mathrm{kNm}=0.693 M_{p}$ Since $\overline{\bar{M}}_{u} \geq 0.67 M_{p}$, the beam capacity is governed by inelastic LTB, and the factored flexural resistance is given by

$M_{r}=\phi 1.15 M_{p}\left(1-0.28 \frac{M_{p}}{\overline{\bar{M}}_{u}}\right)=0.90 \times 1.15 \times 460.0\left(1-0.28 \frac{460.0}{318.8}\right)=283.7 k N m \leq M_{p}$

\section{$\underline{\text { Finite Element Solution }}$}


Given that $M_{u F E A}=333 \mathrm{kNm}$, the factored flexural resistance would be

$$
M_{r}=\phi 1.15 M_{p}\left(1-0.28 \frac{M_{p}}{M_{u F E A}}\right)=0.90 \times 1.15 \times 460.0\left(1-0.28 \frac{460.0}{333}\right)=291.9 \mathrm{kNm}
$$

Therefore, for the case of $F_{y}=400 \mathrm{MPa}$, the Canadian Standard solution over-predicts the beam capacity by $5.6 \%$ compared to the finite element solution while the proposed modified solution under-predicts the critical moment by $2.8 \%$.

For the case of the higher yield strength steel $F_{y}=480 \mathrm{MPa}$, the plastic moment increases to $M_{p}=Z_{x} F_{y}=552.0 \mathrm{kNm}$ and the design is found to be governed by elastic lateral torsional buckling. The CAN-CSA solution predicts a resisting moment of $M_{r}=\phi \bar{M}_{u}=320.7 \mathrm{kNm}$ while the proposed modified procedure predicts a resisting moment of $M_{r}=\phi \overline{\bar{M}}_{u}=286.9 \mathrm{kNm}$. These values compare with $M_{r}=\phi M_{u F E A}=300.0 \mathrm{kNm}$ as based on the FEA solution. In this case, the Canadian standards underestimate the critical moment by $6.9 \%$ while the modified procedure underestimates it by $4.4 \%$

\section{Summary, Conclusions and Recommendations}

(1) A buckling parametric study consisting of 42 runs was conducted based on shell FEA on common size beams with typical double angle cleat connections. The analyses have shown that such members undergo some distortional effects. Also, angle cleat connections were shown to provide only partial twist restraint to member ends.

(2) On average, for the beam and connection configurations investigated, FEA is found to predict critical moments in line with those based on design standards. However, some scatter is observed compared to standard design values. The present Canadian standard provisions provide the best agreement with FEA results with 20 out of 42 cases being overestimated. Comparatively, the American standards, Eurocode guide, and Australian standards overestimate the critical moments in 33,39 , and 41 cases respectively.

(3) Starting with present standard provisions, the present study developed three modifiers to be applied to the critical moment equations: (1) a coefficient for partial twist restraint, (2) a distortional coefficient, and (3) a standard consistency coefficient.

(4) The twist stiffness coefficient is based on an energy formation and successfully incorporates the effect of partial twisting restraint provided by cleat angle connections on the critical moments of beams. The distortional 
coefficient is based on regression analysis and captures the reduction in critical moments based on the geometric parameters of the member.

(5) The proposed design methodology consistently yields predictions in closer agreement to shell based FEA results than all those based on all four standards examined.

(6) The quality of the solution presented herein hinges on the validity of the FEA model developed. In this respect, it is worthwhile to note that similar Abaqus S4R shell modeling has been validated against full-scale LTB fullscale tests for Gerber beam systems (Nowzartash et al. 2011). Also, it was shown to approach the classical flexural and torsional buckling solutions for columns (Dabbas 2002). Through comparisons with beam FEA solutions, similar S4R shell models were successful to quantify the effect of distortional effects on lateral buckling resistance in portal frames (Wu and Mohareb 2013), LTB of beams with doubly symmetric sections (Erkmen and Mohareb 2008 and Wu and Mohareb 2011), and LTB of beams and beam columns with monosymmetric sections (Erkmen and Mohareb 2008 and Saharei et al. 2015). Nevertheless, it is still desirable to conduct careful experimental studies involving the specific connection details investigated in the present study in order to (a) assess the impact of the simplifications introduced in FEA when modelling the connections, (b) quantify the critical moments and compare them with the present predictions, and (c) experimentally verify and observe the end twist effects and distortional phenomena predicted by the present FEA model.

\section{Acknowledgments:}

The authors gratefully acknowledge funding from the Natural Science and Engineering Research Council of Canada (NSERC) to the second author.

\section{References:}

Ádány, S., and Schafer, B.W. 2008. A full modal decomposition of thin-walled, single-branched open cross-section members via the constrained finite strip method, Journal of Constructional Steel Research, 64:12-29.

AISI S100-07 (2007), North American Specification for Design of Cold-Formed Steel Structural Members, American Iron and Steel Institute, Washington, D. C.

American Institute of Steel Construction (AISC). 2005. Specification for structural steel buildings. Chicago, IL. AS 4100. 1998. Steel Structures, Standards Association of Australia. Sydney, Australia. 
Bradford, M. A. and Trahair, N. S. 1981. Distortional Buckling of I-Beams, Journal of the Structural Division, ASCE, 107:355-70.

Bradford, M. A. and Trahair, N. S. 1982. Distortional buckling of thin-web beam-columns, Engineering Structures, $4: 2-10$

Bradford, M. A. 1985. Distortional buckling of monosymmetric I-beams, Journal of Constructional Steel Research, $5: 123-36$.

Bradford, M. A. 1986. Inelastic distortional buckling of I-beams, Computers \& Structures, 24:923-33.

Bradford, M. A. 1988. Buckling of elastically restrained beams with web distortions, Thin-Walled Structures, 6:287-304.

Bradford, M. A. 1990. Stability of mono-symmetric beam-columns with thin webs, Journal of Constructional Steel Research, 15:323-39.

Bradford, M. A. 1992a. Buckling of doubly-symmetric cantilevers with slender webs, Engineering Structures, $14: 327-34$.

Bradford, M. A. 1992b. Lateral-Distortional buckling of steel I-section members, Journal of Constructional Steel Research, 23:97-116.

Bradford, M.A., and Ronagh, H. R. 1997. Generalized elastic buckling of restrained I-beams by FEM, Journal Structural Engineering, ASCE, 123: 1631-37.

CISC (2010) Handbook of Steel Construction, Tenth Edition, Canadian Institute of Steel Construction, Markham, Ontario, Canada

CSA. 2014. Limit states design of steel structures. Standard CAN/CSA-S16-14, Canadian Standards Association, Mississauga, Ontario

Dekker, N.W., and Kemp, A. R. 1998. A simplified distortional buckling model for doubly symmetrical I-sections, Canadian Journal of Civil Engineering, 25:718-27.

Chen, W.E.I., and Ye, J. 2010. Elastic lateral and restrained distortional buckling of doubly symmetric I-beams, International Journal of Structural Stability and Dynamics, 10. pp. 983-1016

Dabbas, A. (2002), “Lateral Stability of Partially Restrained Cantilever Supports”, M. Eng. Report, University of Ottawa, ON, Canada 
Dekker, N.W., and Kemp, A. R. 1998. A simplified distortional buckling model for doubly symmetrical I-sections, Canadian Journal of Civil Engineering, 25:718-27.

Dowswell, B. (2004). Lateral-Torsional Buckling of Wide Flange Cantilever Beams, Engineering Journal, AISC, 41:85-91.

Eurocode 3. 2003: Design of steel structures Part 1-1: general rules and rules for buildings, European Committee for Standardization (CEN), Brussels, Belgium.

Erkmen, R. E. and Mohareb, M., (2008), Buckling Analysis of Thin-walled Open Members - A Finite Element Formulation", Thin-walled structures, Vol. 46(6), pp 618-636

Hancock, G. J. 1978. Local, Distortional, and Lateral Buckling of I-Beams. Journal of the Structural Division, 104: 1787-98.

Hancock, G.J., Bradford, M.A., and Trahair, N.S. 1980. Web distortion and flexural-torsional buckling, Journal of the Structural Division, ASCE, 106:1557-71

Hassan, R. and Mohareb, M. (2012), Distortional lateral torsional buckling analysis for beams of wide flange crosssections, 3rd International Structural Specialty Conference, CSCE, Edmonton, Alberta

Hughes, O., and Ma, M. 1996a. Lateral distortional buckling of monosymmetric beams under point load, Journal of Engineering Mechanics, ASCE, 122:1022-29.

Johnson, C. P., and Will, K. M. 1974. Beam Buckling by Finite Element Procedure, Journal of the Structural Division, 100: 669-85.

Kalkan, I., and Buyukkaragoz, A. (2012). A numerical and analytical study on distortional buckling of doublysymmetric steel I-beams, Journal of Constructional Steel Research, 70:289-297

Ma, M., and Hughes, M. 1996b. Lateral distortional buckling of monosymmetric I-beams under distributed vertical load, Thin-Walled Structures, 26:123-145

Nowzartash F., Markiz N., and Mohareb, M. 2012, Analysis and Testing of Gerber Frames for Lateral Stability, Third International Specialty Conference, Canadian Society of Civil Engineering, Edmonton, Canada, May 25-28 Ng, M. L-H., and Ronagh, H. R. 2004. An analytical solution for the elastic lateral-distortional buckling of I-section beams. Advances in Structural Engineering, 7:189-200.

Pezeshky, P., and Mohareb, M.2014a. Distortional theory for the analysis of wide flange steel beams, Engineering Structures, 75:181-196 
Pezeshky, P, and Mohareb, M 2014b. Objective measures for characterizing distortion in wide flange steel sections, 4th International Structural Specialty Conference, Halifax, Nova Scotia, Canada, May 28- 31

Pezeshky, P. and Mohareb, M., 2015. Finite Element Formulations for the Distortional Analysis of Wide Flange Steel Beams, Journal of Engineering Mechanics, 10.1061/(ASCE)EM.1943-7889.0000984 , 04015071.

Pi, Y., and Trahair, N. 2000. Distortion and warping at beam supports. Journal of Structural Engineering, 126:127987.

Poon, C. P. and Ronagh, H. R. (2004). Distortional Buckling of I-Beams by Finite Element Method, Advances in Structural Engineering, 7(1), 71-80

Rajasekaran, S., and Murray D. W. 1973. Coupled Local Buckling in Wide-Flange Beam-Columns, Journal of the Structural Division, 99: 1003-23

Roberts, T. M. and Jhita, P. S. (1983) Lateral, local and distortional buckling of I-beams, Thin-Walled Structures, 1:289-308.

Sahraei, A., Wu, L., and Mohareb, M. 2015. Finite Element Formulation for Lateral Torsional Buckling Analysis of Shear Deformable Mono-symmetric Thin-walled Members, Thin-Walled Structures, 89, 212-226

Samanta, A., and Kumar, A. 2006. Distortional buckling in monosymmetric I-beams, Thin-Walled Structures, 44: $51-56$.

Samanta, A., and Kumar, A. 2008. Distortional buckling in braced-cantilever I-beams, Thin-Walled Structures, 46:637-645.

Timoshenko, S. P. and Gere, J. M. (1961), Theory of Elastic Stability, McGraw Hill, New York

Vrcelj Z., and Bradford M.A., (2006). Elastic distortional buckling of continuously restrained I-section beamcolumn, Journal of Constructional Steel Research, 62:223-230

Vlasov V. Z. 1961. Thin walled elastic beams, Available from Office of Technical Services, US Department of Commerce, Washington, D.C.: Israel Program for Scientific Translations. 2nd ed, Jerusalem, Israel

Wang, C.M., Chin C.K., and Kitipornchai, S. 1991. Parametric study on distortional buckling of monosymmetric beam-columns, Journal of Constructional Steel Research, 18:89-110

Wu, L. and Mohareb, M. 2011. Buckling Formulation for Shear Deformable Thin-Walled Members- II. Finite Element Formulation, Thin-walled Structures, 49(1), pp. 208-222 
Wu, L. and Mohareb M., 2013. Finite Element Formulation for the Lateral Torsional Buckling of Plane Frames, Journal of Engineering Mechanics, 139(4), 512-524

Zirakian, T. and Showkati, H. 2007. Experiments on Distortional Buckling of I-beams, Journal of Structural Engineering, 133: 109-1017.

Zinoviev, I. and Mohareb, M. 2004. "Analysis and Design of Laterally Unsupported frames for out-of-plane stability”, Canadian Journal of Civil Engineering, Vol. 31(3), pp. 440-452

Zirakian, T. 2008. Elastic distortional buckling of doubly symmetric I-shaped flexural members with slender webs, Thin-Walled Structures, 46: 466-475 


\section{List of Figures}

Fig. 1 (a) Web cleat connection at a beam end (b) LTB under the Vlasov Assumption, (c) Classical LTB and (d) Distortional LTB

Fig. 2 -Boundary Conditions and Abaqus model representation of (a) Radius of influence and (b) Fasteners

Fig. 3 - FEA results (a) $M_{F E A} / M_{u}$ ratio (b) lateral displacement profile at beam ends

Fig. 4- Distortion in two beams with identical relative twist stiffness; (a) Run 8c with W310x52 section and an $8.7 \mathrm{~mm}$ thick cleat angle; and (b) Run 15 with W310x21 section and a $6.4 \mathrm{~mm}$ thick cleat angle.

\section{List of Tables}

Table 1 Results of the parametric study

Table 2 Comparison of buckling solutions and development of design coefficients

Table 3 Critical moments for a 4.5m span W410x39 beam with 2-L76x76x4.8 cleat angles at both ends Table 4 Critical moment for a $4.5 \mathrm{~m}$ span W410x39 beam with 2-L76x76x9.5 cleat angles at both ends 


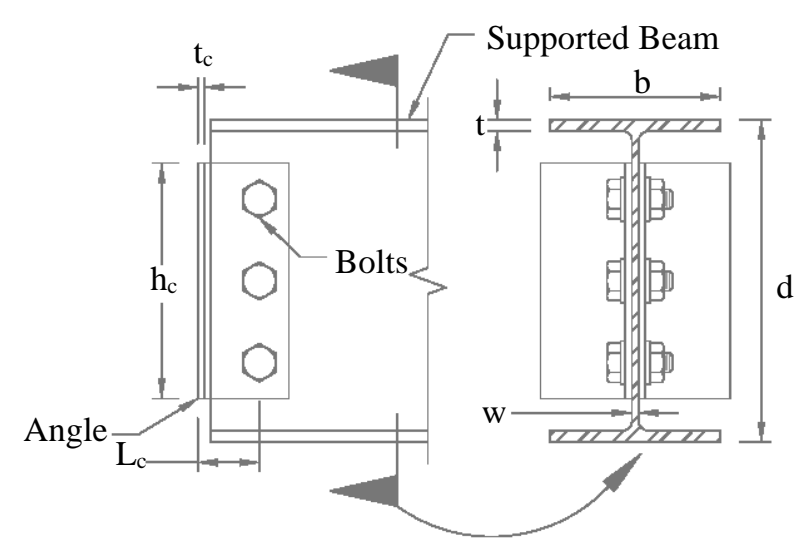

(a)

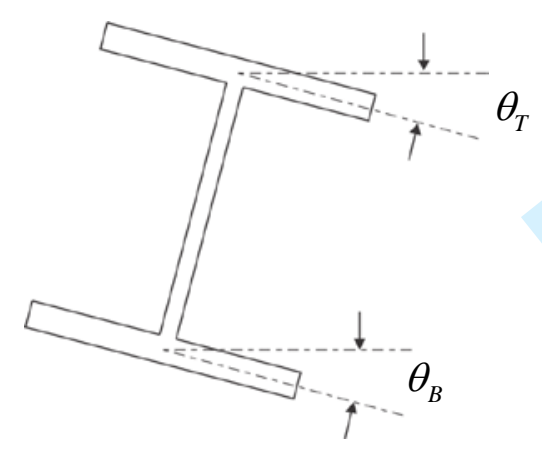

(c) $\theta_{T}=\theta_{B}$

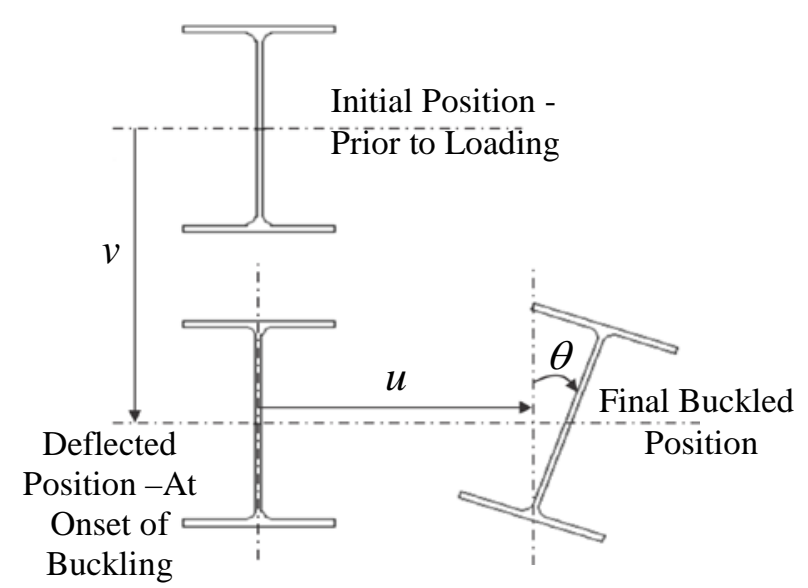

(b)

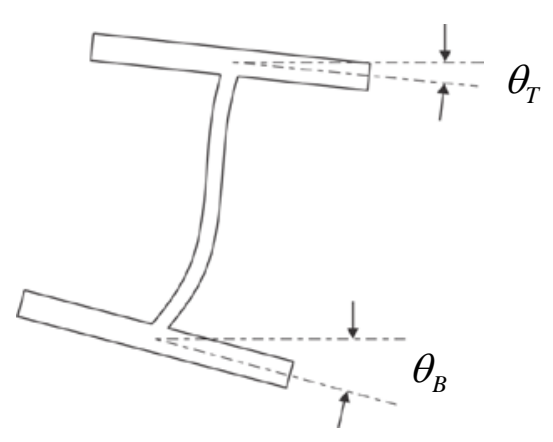

(d) $\theta_{T} \neq \theta_{B}$ 


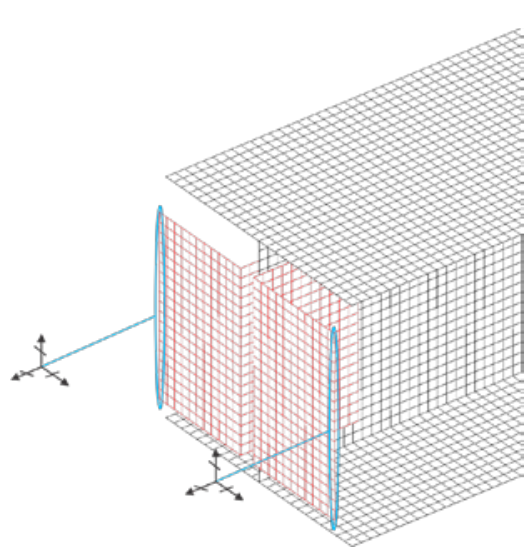

(a)

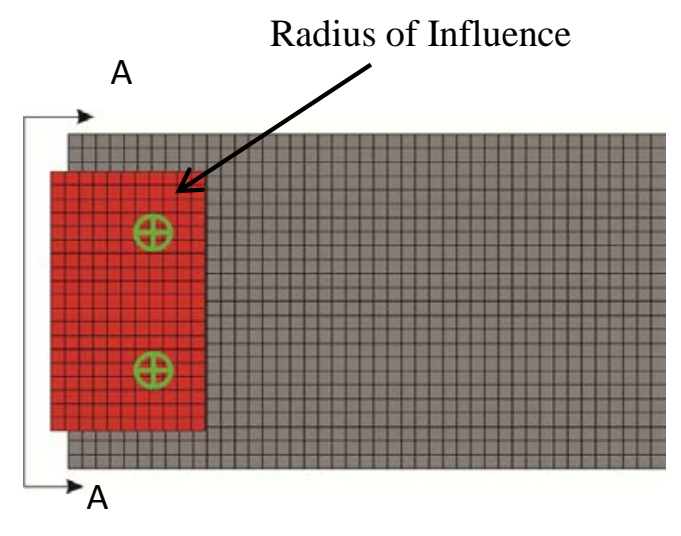

(b)

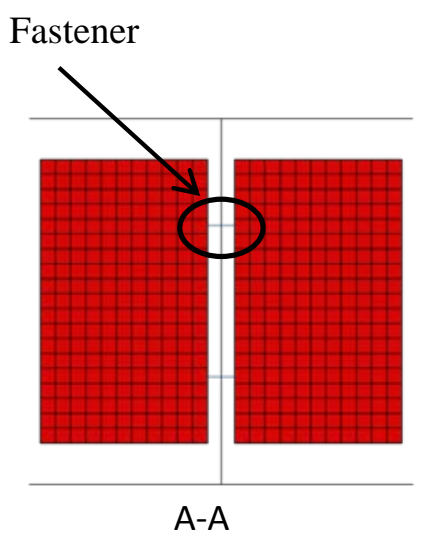

(c) 


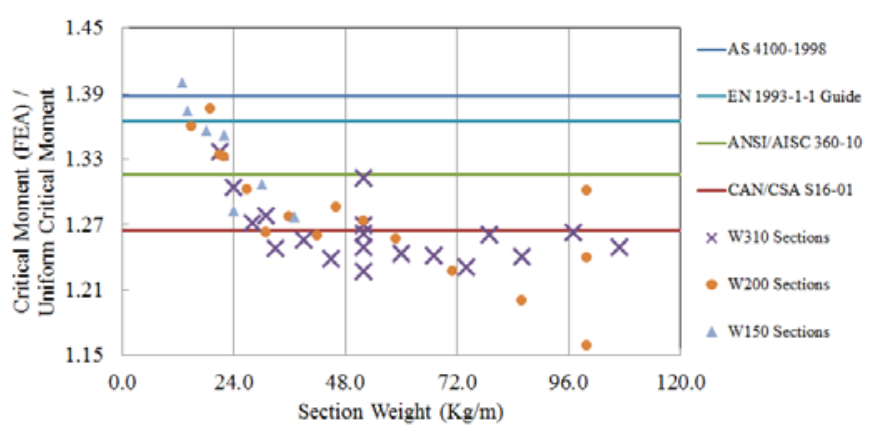

(a)

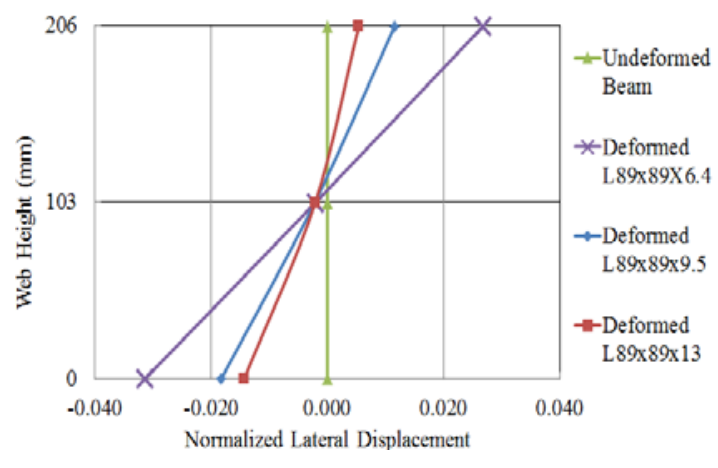

(b) 


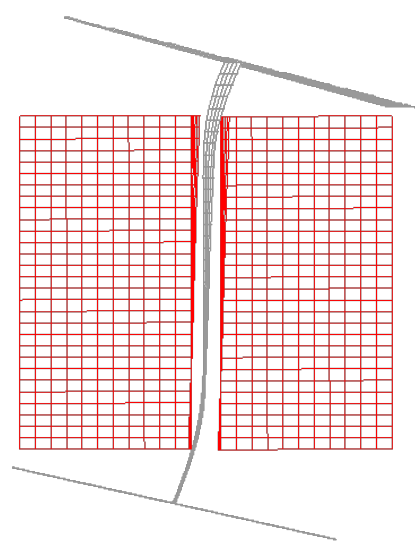

(a)

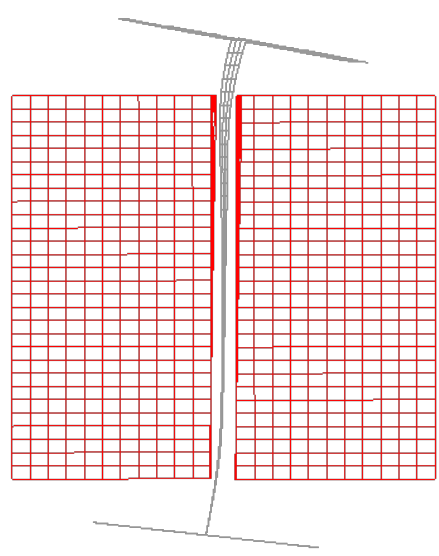

(b) 
Table 1 Results of the parametric study

\begin{tabular}{|c|c|c|c|c|c|c|c|}
\hline 1 & 2 & 3 & 4 & 5 & 6 & 7 & 8 \\
\hline & \multicolumn{2}{|c|}{ Beam geometry } & \multicolumn{4}{|c|}{ Cleat geometry* } & Cri \\
\hline & Section & span (mm) & section & $\begin{array}{l}\text { height hc } \\
\text { (mm) }\end{array}$ & $\begin{array}{l}\text { Twisting } \\
\text { stiffness R } \\
\text { (kNm/rad) }\end{array}$ & $\begin{array}{c}\text { Relative twist } \\
\text { stiffness } \alpha\end{array}$ & $\begin{array}{l}\text { Mu Classical } \\
\text { Solution }\end{array}$ \\
\hline 1 & W310x107 & 12000 & L89x89x6.4 & 230 & 58.8 & 0.157 & 351 \\
\hline 2 & W310x97 & 12000 & L89x89x6.4 & 230 & 58.8 & 0.122 & 293 \\
\hline 3 & W310x86 & 11200 & L89x89x6.4 & 230 & 58.8 & 0.117 & 233 \\
\hline 4 & W310x79 & 10500 & L89x89×6.4 & 230 & 58.8 & 0.0985 & 208 \\
\hline 5 & W310x74 & 8200 & L89x89x6.4 & 230 & 58.8 & 0.138 & 214 \\
\hline 6 & W310x67 & 7700 & L89x89x6.4 & 230 & 58.8 & 0.114 & 189 \\
\hline 7 & W310x60 & 7200 & L89x89x6.4 & 230 & 58.8 & 0.0972 & 169 \\
\hline 8 & W310x52 & 5700 & L89x89x6.4 & 230 & 58.8 & 0.112 & 153 \\
\hline $8 a$ & W310x52 & 5700 & L89x89x13 & 230 & 493 & 0.0134 & 153 \\
\hline $8 b$ & W310x52 & 5700 & L89x89×9.5 & 230 & 192 & 0.0343 & 153 \\
\hline $8 c$ & W310x52 & 5700 & L89x89x8.7 & 230 & 146 & 0.0451 & 153 \\
\hline $8 d$ & W310x52 & 5700 & L89x89x7.9 & 230 & 110 & 0.0596 & 153 \\
\hline 9 & W310x45 & 5300 & L89x89x6.4 & 230 & 58.8 & 0.0894 & 129 \\
\hline 10 & W310x39 & 5400 & L89x89x6.4 & 230 & 58.8 & 0.064 & 100 \\
\hline 11 & W310x31 & 5000 & L89x89x6.4 & 230 & 58.8 & 0.0474 & 77.4 \\
\hline 12 & W310×33 & 3100 & L89x89x6.4 & 230 & 58.8 & 0.0975 & 83.7 \\
\hline 13 & W310x28 & 2900 & L89x89x6.4 & 230 & 58.8 & 0.0802 & 71.2 \\
\hline 14 & W310×24 & 2600 & L89x89x6.4 & 230 & 58.8 & 0.0679 & 59.1 \\
\hline 15 & W310x21 & 2800 & L89x89x6.4 & 230 & 58.8 & 0.0451 & 42.8 \\
\hline 16 & W200×100 & 12000 & L89x89x13 & 150 & 359 & 0.0381 & 288 \\
\hline $16 a$ & W200x100 & 12000 & L89x89x9.5 & 150 & 125 & 0.109 & 288 \\
\hline $16 b$ & W200x100 & 12000 & L89x89x6.4 & 150 & 38.3 & 0.358 & 288 \\
\hline 17 & W200x86 & 12000 & L89x89x6.4 & 150 & 38.3 & 0.238 & 217 \\
\hline 18 & W200x71 & 12000 & L89x89x6.4 & 150 & 38.3 & 0.14 & 150 \\
\hline 19 & W200x59 & 10300 & L89x89x6.4 & 150 & 38.3 & 0.095 & 119 \\
\hline 20 & W200x52 & 10400 & L89x89x6.4 & 150 & 38.3 & 0.0663 & 92.7 \\
\hline 21 & W200x46 & 9300 & L89x89x6.4 & 150 & 38.3 & 0.0531 & 81.4 \\
\hline 22 & W200x42 & 7200 & L89x89x6.4 & 150 & 38.3 & 0.069 & 80.8 \\
\hline 23 & W200x36 & 7100 & L89x89x6.4 & 150 & 38.3 & 0.0473 & 62 \\
\hline 24 & W200x31 & 5100 & L89x89x6.4 & 150 & 38.3 & 0.06 & 60.4 \\
\hline 25 & W200x27 & 5000 & L89x89x6.4 & 150 & 38.3 & 0.0397 & 44.5 \\
\hline 26 & $W 200 \times 21$ & 4500 & L89x89x6.4 & 150 & 38.3 & 0.0277 & 34.2 \\
\hline 27 & W200x22 & 3400 & L89x89x6.4 & 150 & 38.3 & 0.048 & 38.9 \\
\hline 28 & W200x19 & 3400 & L89x89x6.4 & 150 & 38.3 & 0.0331 & 29.1 \\
\hline 29 & W200×15 & 3100 & L89x89x6.4 & 150 & 38.3 & 0.0236 & 22.4 \\
\hline 30 & W150x37 & 8200 & L89x89x6.4 & 100 & 25.6 & 0.0742 & 56.8 \\
\hline 31 & W150x30 & 7600 & L89x89x6.4 & 100 & 25.6 & 0.0434 & 40 \\
\hline 32 & $W 150 \times 22$ & 6100 & L89x89x6.4 & 100 & 25.6 & 0.026 & 28.8 \\
\hline 33 & W150x24 & 4800 & L89x89x6.4 & 100 & 25.6 & 0.0627 & 34.7 \\
\hline
\end{tabular}




\begin{tabular}{|c|c|c|c|c|c|c|c|}
\hline 34 & W150x18 & 3800 & L89x89x6.4 & 100 & 25.6 & 0.0362 & 24.6 \\
\hline 35 & W150x14 & 3600 & L89x89x6.4 & 100 & 25.6 & 0.0204 & 16.2 \\
\hline 36 & $W 150 \times 13$ & 3500 & L89x89x6.4 & 100 & 25.6 & 0.0175 & 14.4 \\
\hline
\end{tabular}




\begin{tabular}{|c|c|c|}
\hline 9 & 10 & 11 \\
\hline \multicolumn{2}{|c|}{ cal moments (kNm) } & \multirow[b]{2}{*}{$\begin{array}{l}\text { End twist/ } \\
\text { midspan twis }\end{array}$} \\
\hline $\begin{array}{l}\text { M FEA } \\
\text { Solution }\end{array}$ & $9 / 8$ & \\
\hline 439.0 & 1.249 & 0.0728 \\
\hline 369.5 & 1.262 & 0.0629 \\
\hline 288.7 & 1.241 & 0.0669 \\
\hline 262.8 & 1.261 & 0.0579 \\
\hline 263.4 & 1.231 & 0.0728 \\
\hline 234.3 & 1.241 & 0.0674 \\
\hline 210.4 & 1.243 & 0.0672 \\
\hline 187.8 & 1.227 & 0.0801 \\
\hline 200.8 & 1.312 & 0.0403 \\
\hline 194.3 & 1.270 & 0.0549 \\
\hline 193.1 & 1.262 & 0.0572 \\
\hline 191.2 & 1.250 & 0.0644 \\
\hline 160.2 & 1.239 & 0.0782 \\
\hline 125.6 & 1.256 & 0.0699 \\
\hline 98.9 & 1.278 & 0.0664 \\
\hline 104.4 & 1.248 & 0.0752 \\
\hline 90.5 & 1.272 & 0.0694 \\
\hline 77.1 & 1.304 & 0.0594 \\
\hline 57.2 & 1.337 & 0.0419 \\
\hline 374.2 & 1.301 & 0.0565 \\
\hline 356.7 & 1.240 & 0.0859 \\
\hline 333.3 & 1.159 & 0.1643 \\
\hline 260.4 & 1.200 & 0.1248 \\
\hline 183.7 & 1.227 & 0.0945 \\
\hline 150.0 & 1.257 & 0.0719 \\
\hline 118.1 & 1.273 & 0.0583 \\
\hline 104.6 & 1.286 & 0.0514 \\
\hline 101.8 & 1.260 & 0.0647 \\
\hline 79.2 & 1.277 & 0.0535 \\
\hline 76.2 & 1.263 & 0.0672 \\
\hline 57.9 & 1.302 & 0.0488 \\
\hline 45.7 & 1.334 & 0.0388 \\
\hline 51.9 & 1.332 & 0.0437 \\
\hline 40.1 & 1.376 & 0.0254 \\
\hline 30.4 & 1.360 & 0.0343 \\
\hline 72.6 & 1.278 & 0.0648 \\
\hline 52.3 & 1.307 & 0.0433 \\
\hline 39.0 & 1.352 & 0.0227 \\
\hline 44.5 & 1.283 & 0.0575 \\
\hline
\end{tabular}




\begin{tabular}{c|c|c|}
33.3 & 1.356 & 0.0235 \\
\hline 22.3 & 1.375 & 0.017 \\
\hline 20.1 & 1.401 & 0.0078 \\
\hline Minimum & 1.159 & 0.008 \\
\hline Average & 1.281 & 0.061 \\
\hline Maximum & 1.401 & 0.164 \\
\hline
\end{tabular}


Table 2 Comparison of buckling solutions and development of design coefficients

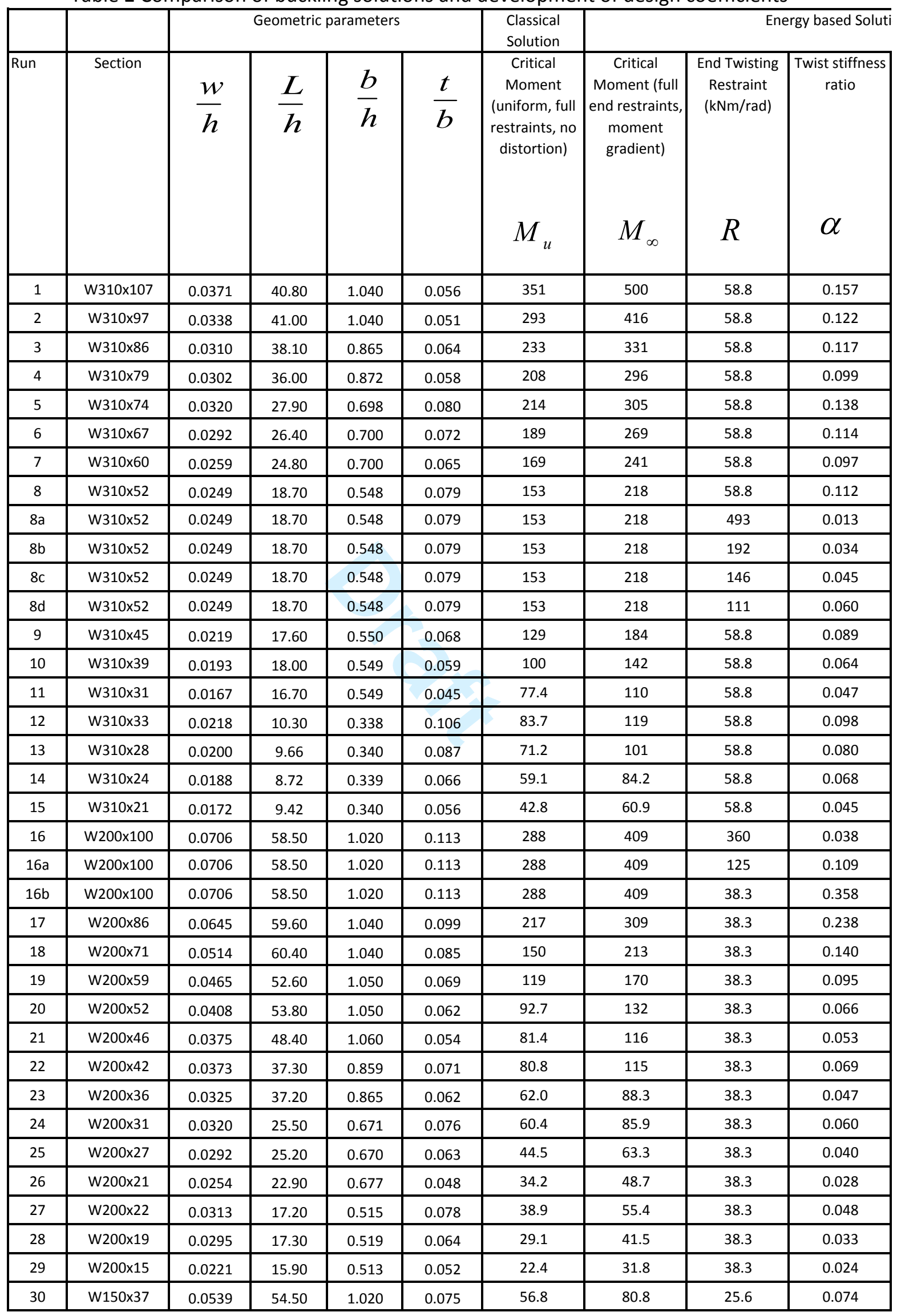




\begin{tabular}{|c|c|c|c|c|c|c|c|c|c|}
\hline 31 & W150x30 & 0.0447 & 51.50 & 1.040 & 0.061 & 40 & 56.9 & 25.6 & 0.043 \\
\hline 32 & W150x22 & 0.0399 & 42.00 & 1.050 & 0.043 & 28.8 & 41 & 25.6 & 0.026 \\
\hline 33 & W150x24 & 0.0441 & 32.10 & 0.681 & 0.101 & 34.7 & 49.4 & 25.6 & 0.063 \\
\hline 34 & W150x18 & 0.0398 & 26.00 & 0.699 & 0.070 & 24.6 & 35 & 25.6 & 0.036 \\
\hline 35 & W150x14 & 0.0298 & 24.90 & 0.692 & 0.055 & 16.2 & 23 & 25.6 & 0.020 \\
\hline \multirow[t]{4}{*}{36} & W150x13 & 0.0300 & 24.50 & 0.699 & 0.049 & 14.4 & 20.5 & 25.6 & 0.018 \\
\hline & minimum & 0.0167 & 8.7200 & 0.3380 & 0.0434 & & & & \\
\hline & average & 0.035 & 31.505 & 0.741 & 0.071 & & & & \\
\hline & maximum & 0.0706 & 60.4000 & 1.0600 & 0.1130 & & & & \\
\hline
\end{tabular}




\begin{tabular}{|c|c|c|c|c|c|c|}
\hline \multicolumn{2}{|l|}{ on } & \multicolumn{2}{|c|}{ FEA based Solution } & \multicolumn{3}{|c|}{ Regression Results } \\
\hline $\begin{array}{c}\text { Partial Twist } \\
\text { Restraint } \\
\text { Coefficient }\end{array}$ & $\begin{array}{c}\text { Critical } \\
\text { Moment } \\
\text { (modified for } \\
\text { end restraints, } \\
\text { moment } \\
\text { gradient) } \\
M_{0}\end{array}$ & \begin{tabular}{|l} 
Distortional \\
Critical \\
Moment
\end{tabular} & $D_{F E A}$ & $\begin{array}{c}\text { Distortional } \\
\text { Coeffient based } \\
\text { on regression } \\
\text { analysis }\end{array}$ & \begin{tabular}{|c|} 
Approximate \\
Distortional Critical \\
Moment \\
$M_{d}=D M_{0}$
\end{tabular} & $\begin{array}{c}\text { Ratio } \\
M_{d} / M_{F E A}\end{array}$ \\
\hline 0.892 & 446 & 439 & 0.984 & 0.955 & 426.1 & 0.971 \\
\hline 0.913 & 380 & 369 & 0.971 & 0.950 & 361.1 & 0.979 \\
\hline 0.916 & 303 & 289 & 0.954 & 0.937 & 283.8 & 0.982 \\
\hline 0.928 & 275 & 263 & 0.956 & 0.945 & 259.7 & 0.988 \\
\hline 0.903 & 275 & 263 & 0.956 & 0.943 & 259.3 & 0.986 \\
\hline 0.918 & 247 & 234 & 0.947 & 0.945 & 233.4 & 0.997 \\
\hline 0.929 & 224 & 210 & 0.938 & 0.945 & 211.6 & 1.007 \\
\hline 0.919 & 200 & 188 & 0.940 & 0.939 & 187.8 & 0.999 \\
\hline 0.989 & 216 & 201 & 0.931 & 0.939 & 202.8 & 1.009 \\
\hline 0.973 & 212 & 194 & 0.915 & 0.939 & 199.1 & 1.026 \\
\hline 0.965 & 210 & 193 & 0.919 & 0.939 & 197.2 & 1.022 \\
\hline 0.954 & 208 & 191 & 0.918 & 0.939 & 195.3 & 1.023 \\
\hline 0.934 & 172 & 160 & 0.930 & 0.944 & 162.4 & 1.015 \\
\hline 0.951 & 135 & 126 & 0.933 & 0.946 & 127.6 & 1.013 \\
\hline 0.963 & 106 & 98.9 & 0.933 & 0.955 & 101.2 & 1.024 \\
\hline 0.928 & 110 & 104 & 0.945 & 0.917 & 100.9 & 0.970 \\
\hline 0.94 & 94.9 & 90.5 & 0.954 & 0.934 & 88.7 & 0.980 \\
\hline 0.949 & 79.9 & 77.1 & 0.965 & 0.957 & 76.5 & 0.992 \\
\hline 0.965 & 58.8 & 57.2 & 0.973 & 0.963 & 56.6 & 0.990 \\
\hline 0.97 & 397 & 374 & 0.942 & 0.976 & 387.5 & 1.036 \\
\hline 0.921 & 377 & 357 & 0.947 & 0.976 & 368.0 & 1.031 \\
\hline 0.794 & 325 & 333 & 1.025 & 0.976 & 317.2 & 0.953 \\
\hline 0.848 & 262 & 260 & 0.992 & 0.971 & 254.3 & 0.978 \\
\hline 0.902 & 192 & 184 & 0.958 & 0.943 & 181.1 & 0.984 \\
\hline 0.93 & 158 & 150 & 0.949 & 0.955 & 150.8 & 1.006 \\
\hline 0.95 & 125 & 118 & 0.944 & 0.943 & 117.9 & 0.999 \\
\hline 0.959 & 111 & 105 & 0.946 & 0.948 & 105.2 & 1.002 \\
\hline 0.948 & 109 & 102 & 0.936 & 0.951 & 103.6 & 1.016 \\
\hline 0.963 & 85.1 & 79.2 & 0.931 & 0.946 & 80.5 & 1.016 \\
\hline 0.954 & 82 & 76.2 & 0.929 & 0.951 & 78.0 & 1.024 \\
\hline 0.969 & 61.3 & 57.9 & 0.945 & 0.958 & 58.7 & 1.014 \\
\hline 0.978 & 47.6 & 45.7 & 0.960 & 0.966 & 46.0 & 1.006 \\
\hline 0.963 & 53.3 & 51.9 & 0.974 & 0.964 & 51.4 & 0.990 \\
\hline 0.974 & 40.4 & 40.1 & 0.993 & 0.976 & 39.4 & 0.983 \\
\hline 0.981 & 31.2 & 30.4 & 0.974 & 0.967 & 30.2 & 0.993 \\
\hline 0.944 & 76.3 & 72.6 & 0.952 & 0.971 & 74.1 & 1.021 \\
\hline
\end{tabular}




\begin{tabular}{|c|c|c|c|c|c|c|}
\hline 0.966 & 55 & 52.3 & 0.951 & 0.961 & 52.8 & 1.010 \\
\hline 0.979 & 40.2 & 39 & 0.970 & 0.977 & 39.3 & 1.007 \\
\hline 0.952 & 47 & 44.5 & 0.947 & 0.953 & 44.8 & 1.006 \\
\hline 0.972 & 34 & 33.3 & 0.979 & 0.983 & 33.4 & 1.004 \\
\hline 0.984 & 22.6 & 22.3 & 0.987 & 0.969 & 21.9 & 0.982 \\
\hline 0.986 & 20.2 & 20.1 & 0.995 & 0.977 & 19.7 & 0.982 \\
\hline 0.7940 & & & 0.9151 & & & 0.9526 \\
\hline 0.943 & & & 0.954 & & & 1.000 \\
\hline 0.9890 & & & 1.0246 & & & 1.0361 \\
\hline
\end{tabular}


Table 3 Critical moment predictions for a 4.5m span W410x39 beam (with 2-L76x76x4.8 cleat angles at both ends)

\begin{tabular}{|c|c|c|c|c|c|c|c|}
\hline & $\begin{array}{l}\text { Factored Critical } \\
\text { Moment Equation } \\
\left.\text { ( } M_{c r} \text { or } M_{r}\right)\end{array}$ & $\begin{array}{c}\text { Moment } \\
\text { gradient } \\
\text { Factor } \\
\left(C_{s}\right)\end{array}$ & $\begin{array}{l}\text { Partial } \\
\text { twist } \\
\text { restraint } \\
\text { factor } \\
\left(C_{R}\right)\end{array}$ & $\begin{array}{c}\text { Distortion } \\
\text { coefficient } \\
\text { (D) }\end{array}$ & $\begin{array}{l}\text { Consistency } \\
\text { coefficient } \\
\left(S_{s}\right)\end{array}$ & $\begin{array}{l}\text { Critical } \\
\text { Moments } \\
(k N m)\end{array}$ & $\frac{M_{r}}{M_{F E A}}$ \\
\hline $\begin{array}{c}\mathrm{CAN} / \mathrm{CSA} \\
\mathrm{S} 16^{(1)}\end{array}$ & $\phi C_{C A N} M_{u}$ & 1.265 & - & - & - & 109.6 & 0.981 \\
\hline $\begin{array}{l}\text { ANSI/AIC } \\
360-10^{(1)}\end{array}$ & $\phi C_{A I S C} M_{u}$ & 1.316 & - & - & - & 114.1 & 1.021 \\
\hline $\begin{array}{c}\text { CAN/CSA } \\
\text { S16 } \\
\text { Modified }^{(2)}\end{array}$ & $\phi D C_{R} C_{C A N} M_{u}$ & 1.265 & 0.922 & 0.947 & - & 95.7 & 0.857 \\
\hline $\begin{array}{l}\text { ANSI/AISC } \\
\text { 360-10 } \\
\text { Modified }^{(2)}\end{array}$ & $\phi D C_{R} C_{A I S C} M_{u}$ & 1.316 & 0.922 & 0.947 & - & 99.6 & 0.892 \\
\hline $\begin{array}{l}\text { Consistent } \\
\text { Procedure } \\
(\mathrm{CSA})^{(3)}\end{array}$ & $\phi S_{C S A} D C_{R} C_{C S A} M_{u}$ & 1.265 & 0.922 & 0.947 & 1.125 & 107.6 & 0.963 \\
\hline $\begin{array}{l}\text { Consistent } \\
\text { Procedure } \\
(\mathrm{AISC})^{(3)}\end{array}$ & $\phi S_{A I S C} D C_{R} C_{A I S C} M_{u}$ & 1.316 & 0.922 & 0.947 & 1.081 & 107.6 & 0.963 \\
\hline FEA & $\phi M_{F E A}$ & & & & & 111.7 & 1.00 \\
\hline
\end{tabular}

(1) Does not account for distortion or partial twist restraint. Equations based on moment gradient factors in standards.

(2) Equations based on moment gradient factors in standards. Accounts for partial twist restraint and distortion.

(3) Equations are standard independent and account for partial twist restraint and distortion. 
Table 4 Critical moment predictions for a 4.5m span W410x39 beam (supported by 2-L76x76x9.5 at both ends).

\begin{tabular}{|c|c|c|c|c|c|c|c|}
\hline & $\begin{array}{l}\text { Factored Critical } \\
\text { Moment Equation } \\
\left.\text { ( } M_{c r} \text { or } M_{r}\right)\end{array}$ & $\begin{array}{l}\text { Moment } \\
\text { gradient } \\
\text { Factor } \\
\left(C_{s}\right)\end{array}$ & $\begin{array}{l}\text { Partial } \\
\text { twist } \\
\text { restraint } \\
\text { factor } \\
\left(C_{R}\right)\end{array}$ & $\begin{array}{l}\text { Distortion } \\
\text { coefficient } \\
\text { (D) }\end{array}$ & $\begin{array}{l}\text { Consistency } \\
\text { coefficient } \\
\qquad\left(S_{s}\right)\end{array}$ & $\begin{array}{l}\text { Critical } \\
\text { Moments } \\
(k N m)\end{array}$ & $\frac{M_{r}}{M_{F E A}}$ \\
\hline $\begin{array}{c}\text { CAN/CSA } \\
\mathrm{S} 16^{(1)}\end{array}$ & $\phi C_{C A N} M_{u}$ & 1.265 & - & - & - & 109.6 & 0.923 \\
\hline $\begin{array}{l}\text { ANSI/AIC } \\
360-10^{(1)}\end{array}$ & $\phi C_{A I S C} M_{u}$ & 1.316 & - & - & - & 114.1 & 0.961 \\
\hline $\begin{array}{c}\text { CAN/CSA } \\
\text { S16 } \\
\text { Modified }^{(2)}\end{array}$ & $\phi D C_{R} C_{C A N} M_{u}$ & 1.265 & 0.989 & 0.947 & - & 102.6 & 0.864 \\
\hline $\begin{array}{l}\text { ANSI/AISC } \\
360-10 \\
\text { Modified }^{(2)}\end{array}$ & $\phi D C_{R} C_{A I S C} M_{u}$ & 1.316 & 0.989 & 0.947 & - & 106.8 & 0.900 \\
\hline $\begin{array}{c}\text { Consistent } \\
\text { Procedure } \\
(\mathrm{CSA})^{(3)}\end{array}$ & $\phi S_{C S A} D C_{R} C_{C S A} M_{u}$ & 1.265 & 0.989 & 0.947 & 1.125 & 115.4 & 0.972 \\
\hline $\begin{array}{l}\text { Consistent } \\
\text { Procedure } \\
\text { (AISC) }^{(3)}\end{array}$ & $\phi S_{A I S C} D C_{R} C_{A I S C} M_{u}$ & 1.316 & 0.989 & 0.947 & 1.081 & 115.4 & 0.972 \\
\hline FEA & $\phi M_{F E A}$ & & & & & 118.7 & 1.000 \\
\hline
\end{tabular}

(1) Does not account for distortion or partial twist restraint. Equations based on moment gradient factors in standards.

(2) Equations based on moment gradient factors in standards. Accounts for partial twist restraint and distortion.

(3) Equations are standard independent and account for partial twist restraint and distortion. 
Table 3 Critical moment predictions for a 4.5m span W410x39 beam (with 2-L76x76x4.8 cleat angles at both ends)

\begin{tabular}{|c|c|c|c|c|c|c|c|}
\hline & $\begin{array}{l}\text { Factored Critical } \\
\text { Moment Equation } \\
\left(M_{c r} \text { or } M_{r}\right)\end{array}$ & $\begin{array}{c}\text { Moment } \\
\text { gradient } \\
\text { Factor } \\
\left(C_{s}\right)\end{array}$ & $\begin{array}{l}\text { Partial } \\
\text { twist } \\
\text { restraint } \\
\text { factor } \\
\left(C_{R}\right)\end{array}$ & $\begin{array}{c}\text { Distortion } \\
\text { coefficient } \\
\text { (D) }\end{array}$ & $\begin{array}{l}\text { Consistency } \\
\text { coefficient } \\
\left(S_{s}\right)\end{array}$ & $\begin{array}{l}\text { Critical } \\
\text { Moments } \\
(k N m)\end{array}$ & $\frac{M_{r}}{M_{F E A}}$ \\
\hline $\begin{array}{c}\mathrm{CAN} / \mathrm{CSA} \\
\mathrm{S} 16^{(1)}\end{array}$ & $\phi C_{C A N} M_{u}$ & 1.265 & - & - & - & 109.6 & 0.981 \\
\hline $\begin{array}{l}\text { ANSI/AIC } \\
360-10^{(1)}\end{array}$ & $\phi C_{A I S C} M_{u}$ & 1.316 & - & - & - & 114.1 & 1.021 \\
\hline $\begin{array}{c}\text { CAN/CSA } \\
\text { S16 } \\
\text { Modified }^{(2)}\end{array}$ & $\phi D C_{R} C_{C A N} M_{u}$ & 1.265 & 0.922 & 0.947 & - & 95.7 & 0.857 \\
\hline $\begin{array}{l}\text { ANSI/AISC } \\
\text { 360-10 } \\
\text { Modified }^{(2)}\end{array}$ & $\phi D C_{R} C_{A I S C} M_{u}$ & 1.316 & 0.922 & 0.947 & - & 99.6 & 0.892 \\
\hline $\begin{array}{l}\text { Consistent } \\
\text { Procedure } \\
(\mathrm{CSA})^{(3)}\end{array}$ & $\phi S_{C S A} D C_{R} C_{C S A} M_{u}$ & 1.265 & 0.922 & 0.947 & 1.125 & 107.6 & 0.963 \\
\hline $\begin{array}{l}\text { Consistent } \\
\text { Procedure } \\
(\mathrm{AISC})^{(3)}\end{array}$ & $\phi S_{A I S C} D C_{R} C_{A I S C} M_{u}$ & 1.316 & 0.922 & 0.947 & 1.081 & 107.6 & 0.963 \\
\hline FEA & $\phi M_{F E A}$ & & & & & 111.7 & 1.00 \\
\hline
\end{tabular}

(1) Does not account for distortion or partial twist restraint. Equations based on moment gradient factors in standards.

(2) Equations based on moment gradient factors in standards. Accounts for partial twist restraint and distortion.

(3) Equations are standard independent and account for partial twist restraint and distortion. 
Table 4 Critical moment predictions for a 4.5m span W410x39 beam (supported by 2-L76x76x9.5 at both ends).

\begin{tabular}{|c|c|c|c|c|c|c|c|}
\hline & $\begin{array}{l}\text { Factored Critical } \\
\text { Moment Equation } \\
\left.\text { ( } M_{c r} \text { or } M_{r}\right)\end{array}$ & $\begin{array}{l}\text { Moment } \\
\text { gradient } \\
\text { Factor } \\
\left(C_{s}\right)\end{array}$ & $\begin{array}{l}\text { Partial } \\
\text { twist } \\
\text { restraint } \\
\text { factor } \\
\left(C_{R}\right)\end{array}$ & $\begin{array}{l}\text { Distortion } \\
\text { coefficient } \\
\text { (D) }\end{array}$ & $\begin{array}{l}\text { Consistency } \\
\text { coefficient } \\
\qquad\left(S_{s}\right)\end{array}$ & $\begin{array}{l}\text { Critical } \\
\text { Moments } \\
(k N m)\end{array}$ & $\frac{M_{r}}{M_{F E A}}$ \\
\hline $\begin{array}{c}\mathrm{CAN} / \mathrm{CSA} \\
\mathrm{S} 16^{(1)}\end{array}$ & $\phi C_{C A N} M_{u}$ & 1.265 & - & - & - & 109.6 & 0.923 \\
\hline $\begin{array}{l}\text { ANSI/AIC } \\
360-10^{(1)}\end{array}$ & $\phi C_{A I S C} M_{u}$ & 1.316 & - & - & - & 114.1 & 0.961 \\
\hline $\begin{array}{c}\text { CAN/CSA } \\
\text { S16 } \\
\text { Modified }^{(2)}\end{array}$ & $\phi D C_{R} C_{C A N} M_{u}$ & 1.265 & 0.989 & 0.947 & - & 102.6 & 0.864 \\
\hline $\begin{array}{l}\text { ANSI/AISC } \\
360-10 \\
\text { Modified }^{(2)}\end{array}$ & $\phi D C_{R} C_{A I S C} M_{u}$ & 1.316 & 0.989 & 0.947 & - & 106.8 & 0.900 \\
\hline $\begin{array}{l}\text { Consistent } \\
\text { Procedure } \\
(\mathrm{CSA})^{(3)}\end{array}$ & $\phi S_{C S A} D C_{R} C_{C S A} M_{u}$ & 1.265 & 0.989 & 0.947 & 1.125 & 115.4 & 0.972 \\
\hline $\begin{array}{l}\text { Consistent } \\
\text { Procedure } \\
(\mathrm{AISC})^{(3)}\end{array}$ & $\phi S_{A I S C} D C_{R} C_{A I S C} M_{u}$ & 1.316 & 0.989 & 0.947 & 1.081 & 115.4 & 0.972 \\
\hline FEA & $\phi M_{F E A}$ & & & & & 118.7 & 1.000 \\
\hline
\end{tabular}

(1) Does not account for distortion or partial twist restraint. Equations based on moment gradient factors in standards.

(2) Equations based on moment gradient factors in standards. Accounts for partial twist restraint and distortion.

(3) Equations are standard independent and account for partial twist restraint and distortion. 